Article

\title{
Rapid Assessment of a Typhoon Disaster Based on NPP-VIIRS DNB Daily Data: The Case of an Urban Agglomeration along Western Taiwan Straits, China
}

\author{
Yuanmao Zheng ${ }^{1,2}{ }^{(}$, Guofan Shao $^{3}$, Lina Tang ${ }^{1}{ }^{(D)}$, Yuanrong $\mathrm{He}^{4,5}$, Xiaorong Wang ${ }^{4,5}$, \\ Yening Wang ${ }^{1,2}\left(\mathbb{D}\right.$ and Haowei Wang ${ }^{1, *}$ \\ 1 Key Lab of Urban Environment and Health, Institute of Urban Environment, Chinese Academy of Sciences, \\ Xiamen 361021, China \\ 2 University of Chinese Academy of Sciences, Beijing 100049, China \\ 3 Department of Forestry and Natural Resources, Purdue University, West Lafayette, IN 47907, USA \\ 4 College of Computer and Information Engineering, Xiamen University of Technology, Xiamen 361024, China \\ 5 Big Data Institute of Digital Natural Disaster Monitoring in Fujian, Xiamen University of Technology, \\ Xiamen 361024, China \\ * Correspondence: hwwang@iue.ac.cn; Tel.: +86-592-619-0694
}

Received: 6 June 2019; Accepted: 17 July 2019; Published: 19 July 2019

\begin{abstract}
Rapid assessment of natural disasters is essential for disaster analysis and spatially explicit strategic decisions of post-disaster reconstruction but requires timely available data. The recent daily data of the National Polar-Orbiting Partnership Visible Infrared Imaging Radiometer Suite (NPP-VIIRS) day/night band (DNB) provide new opportunities to detect and evaluate natural disasters. Here, we introduce an application of NPP-VIIRS DNB daily data for rapidly assessing the damage of a severe typhoon that struck the urban agglomerations along the western Taiwan Straits in China. Our research explored the methods of rapid identification and extraction of the areas based on changes in nighttime light (NTL) after the typhoon disaster by using a statistical radiation-normalization method. We analyzed the correlations of NTL image derivatives with human population, population density, and gross domestic product (GDP). The strong correlations were found between NTL image light density and population density $\left(R^{2}=0.83\right)$ and between the total nighttime light intensity and GDP $\left(R^{2}=0.96\right)$ at the prefecture level. In addition, we examined the interrelationships between changes in NTL images and the areas affected by the typhoon and proposed a method to predict the affected population. Finally, the affected area and the affected population in the study area could be rapidly retrieved based on the proposed remote sensing method. The overall accuracy was $83.2 \%$ for the detection of the affected population after disaster and the recovery rate of the affected area was $86.9 \%$ in the third week after the typhoon. This research demonstrates that the NTL image-based change detection method is simple and effective, and further explains that the NPP-VIIRS DNB daily data are useful for rapidly assessing affected areas and affected populations after typhoon disasters, and for timely quantifying the degree of recovery at a large spatial scale.
\end{abstract}

Keywords: NPP-VIIRS; DNB daily data; nighttime light; remote sensing; Taiwan Straits; typhoon; disaster statistics; rapid assessment; hurricane

\section{Introduction}

A typhoon is an extreme weather event with excessive destructive force [1] and is one of the most serious natural disasters on Earth. The southeastern coastal areas of China, which are intensively populated and extensively developed, are vulnerable to frequent typhoons. The annual economic losses and casualties caused by typhoon disasters in this region are enormous [2]. With increased 
climate variability in recent decades, many super-typhoons occurred in the northwestern Pacific Ocean [3]. The super-typhoons, characterized by strong winds, heavy rainfall, and storm surges, which can cause extremely high loss of lives and widespread damage to properties and infrastructures, have been widely investigated [4,5].

A rapid and accurate assessment of typhoon disaster impacts is not only a prerequisite for analyzing typhoon disasters and managing typhoon disaster rescues but also the basis for making information-based strategic decisions on post-typhoon reconstruction [6]. Therefore, a rapid assessment of the situation is necessary after any typhoon disasters. Such a rapid assessment refers to the rapid estimation and prediction of disaster-related losses after a typhoon. The timely availability of disaster information is particularly important in this case.

With traditional labor-intensive field survey methods, data collection is inefficient, dangerous, and limited by ground conditions [7], making it difficult to conduct rapid disaster assessment over a large area. Remote sensing images can provide objective, near-real-time, and large-scale surface information and thus, are useful for disaster assessment after typhoons. Compared with optical and radar remote sensing, which mainly identifies ground deformations caused by natural disasters [8], nighttime light (NTL) remote sensing data directly reflects human socioeconomic activities as it records artificial lights from cities, towns, industrial sites, fishing boats, and other human activities $[9,10]$. Typhoon disasters can seriously damage buildings and infrastructures, resulting in power outages and the concomitant reduction in human activities, all of which can cause changes in light output. Thus, NTL can directly reveal the affected area and indirectly estimate the size of the affected population.

At present, two sources of NTL data are available worldwide: One is the Operational Line-scan System of the National Defense Meteorological Satellite Project (DMSP-OLS), and the other is the visible infrared imaging radiometer (VIIRS) day-and-night band (DNB) from the Suomi National Polar-orbit Partnership (S-NPP) satellite. The DMSP-OLS has been used for detecting surface activities at night and producing NTL images since the early 1970s, but it has limitations such as lower radiation accuracy, a low spatial resolution, and lack of onboard calibration [11,12]. The next-generation NPP-VIIRS DNB data are acquired by systems that use on-board calibration to enable the detection of light of extremely low-brightness and thereby provide improved capabilities for NTL observation that overcome some of the limitations of DMSP-OLS images [13]. The NPP-VIIRS DNB data provide global coverage with a revisit time of $12 \mathrm{~h}$ (at about 1:30 a.m. and 1:30 p.m. local time) and provide a spatial resolution of $742 \mathrm{~m}$.

A high correlation exists between NTL data and human activities, and NTL data have the advantages of temporal-spatial continuity, independence, and objectivity. Yearly or monthly composite NTL data are increasingly used as an index to assess various socioeconomic indicators such as gross domestic product (GDP) [14-16], population [17,18], electricity and energy consumption [19-21], carbon emissions [22-24], and urbanization [25,26]. They are also used to extract urban built-up areas [27,28], analyze the evolution of urban agglomerations [29-31], and assess major disaster events [32,33]. However, because of their low temporal resolution, yearly or monthly composite NTL data are not suitable for speedy assessment of disasters.

The use of the DMSP-OLS daily images to assess disasters is limited by the cost of the images and by internal limitations [34]. The NPP-VIIRS DNB daily data, however, are free of charge and readily available for rapid disaster assessment. The daily NTL data from both NPP-VIIRS DNB and DMSP-OLS have been used to monitor power outages caused by typhoons and to assess the impacts of typhoons and other natural disasters. For example, Elvidge et al. [35] overlaid the daily NTL image after hurricane Fran with the DMSP-OLS stable NTL data to form a color-composite image to visually identify the areas without power. Molthan et al. [36] used daily NPP-VIIRS DNB data to produce false-color-composite images of before- and after-hurricane NTL to detect light changes and identify potential areas of power outage. Kohiyama et al. [32] used DMSP-OLS time-series images to evaluate the impact of the 2001 West India earthquake and found that the results of monitoring disaster loss from NTL images were highly consistent with the field-survey data. Cao et al. [37] used NPP-VIIRS images to evaluate the power outage caused by two extreme weather events in the United States 
and found that the power-outage range extracted from NTL images was very close to the results of on-ground investigations. Cole et al. [33] distinguished the NTL images before and after the hurricanes based on NPP-VIIRS DNB and generated percent of normal light (PNL) images and advanced a neural-network model for detecting power outages. Wang et al. [38] used the National Aeronautics and Space Administration (NASA) Black Marble nighttime data (a type of high-quality NTL data from NPP-VIIRS DNB) and PNL to assess disaster-related power outages. Zhao et al. [39] evaluated the power recovery after a hurricane disaster based on NPP-VIIRS images. In the Hurricane Hudhud incident, NPP-VIIRS image-based estimations of the proportion of users without power were consistent with the reported power-outage situation, showing that the NPP-VIIRS DNB daily data were effective for detecting damage and power outage caused by the storm. In summary, the most commonly used methods for detecting changes in NTL remote-sensing images include pixel-based image comparisons before and after events [33,35,37,39] and region-based time-series analyses [32,38].

Because NTL data contain light intensity information, they can reflect social-attribute information and attenuation characteristics of the population and thus, have great potentials for studying population spatial distribution [40]. For example, when analyzing the radiation characteristics of NTL data, Sutton et al. [41] analyzed the relationship between population and NTL data and demonstrated its application potential. Amaral et al. [42] examined the relationship between the Brazilian population and areas in the NTL images. Zhuo et al. [43] used the intensity information from DMSP-OLS data, and simulated population density both inside and outside light patches, whose results were consistent with other estimates but exhibited more spatial heterogeneity and richer information. Yang et al. [18] investigated the population spatialization based on NTL images and different spatial distribution models and reduced the average relative error by $17.7 \%$, which improved the accuracy significantly. Chen et al. [44] showed that NPP-VIIRS data had advantages for retrieving population in small-scale underdeveloped areas and could provide adequate information to determine the population.

It is evident that NTL remote sensing has achieved important theoretical and practical results in natural disaster statistics and for estimating socioeconomic parameters such as population spatialization. However, more research efforts are needed to investigate the use of the NPP-VIIRS DNB daily data for rapid estimations of affected areas and affected population or recovery assessment after typhoon disasters. In this study, NPP-VIIRS DNB is used as a data source to examine the rapid acquisition technology and method for typhoon disasters. We thus focus on investigating how to rapidly identify and extract changes caused by a typhoon by using NTL data and statistical radiation normalization. We also investigate the interrelationships of the affected area derived with NTL data with the area and population affected by the typhoon reported from other sources. The overall methodology will be useful to provide supplementary information and decision support for emergency rescue services to alleviate the problems of insufficient and lagging information on super-typhoon disasters.

\section{Materials}

\subsection{Study Area}

The study area includes 20 cities along the western Taiwan Straits on the eastern coast of China, which belong to one of the national-level urban agglomerations (Figure 1). Fujian Province is the main administrative area within the agglomeration, surrounded by Zhejiang, Jiangxi, and Guangdong Provinces. The total area of the agglomeration is approximately $270,000 \mathrm{~km}^{2}$. This agglomeration is one of the key development regions in China's regional development strategy and connects the Yangtze River delta in the north and the Pearl River delta in the south. It forms an essential part of China's coastal economic belt and is at the forefront of cross-strait cooperation and exchanges. The study area is a special geographical location characterized by a high incidence of typhoon disasters [45]. On the morning of 11 July, 2018, the region was hit by the super typhoon Maria [46], which was one of the most intense tropical cyclones in China's that year, with a central pressure of $920 \mathrm{hPa}$ (Figure 1b). The super typhoon Maria led to the shutdown of the high-speed railway in Fujian, Zhejiang, and other 
provinces, a large number of power outages, and a large area of damage, affecting 1173000 people in Fujian, Jiangxi, and Zhejiang Provinces [47].
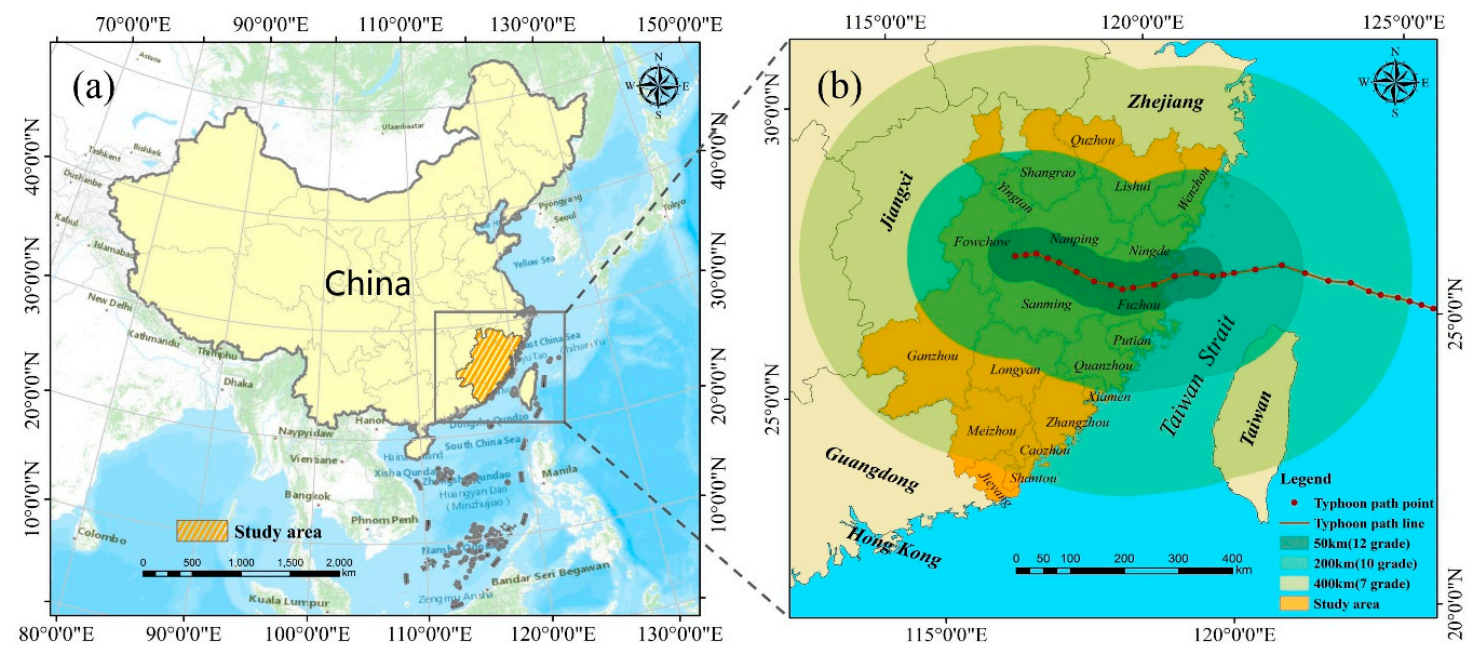

Figure 1. (a) The geographical location of the research area, (b) the path of super typhoon Maria.

\subsection{Data Source}

In this study, the NTL data were obtained from the National Oceanic and Atmospheric Administration/National Geophysical Data Center (NOAA NGDC, NOAA's National Geophysical Data Center, https://ngdc.noaa.gov/eog/viirs/download_dbs.html). The data were acquired by the visible infrared imaging radiometer (VIIRS) on the Suomi-NPP satellite and contained a yearly composite dataset for 2016, two monthly composite datasets from May to June 2018, and 32 daily DNB datasets (acquired at night) from 1 July to 1 August, 2018 [48]. At the same time, for the purpose of the typhoon disaster assessment, we used population, GDP, and various socioeconomic statistical data. In addition, the path of super typhoon No. 201808 "Maria" was derived from the China Central Meteorological Observatory Typhoon Network [46]. The vector administrative boundary of the research area was obtained from the 1:4 million prefecture-level city- and county-level administration boundary data released by the National Basic Geographic Information Center. The $30 \mathrm{~m}$ resolution land-cover data of the research area was obtained from the National Geographic Center of China [49]. The details of the data used in this study are listed in Table 1.

Table 1. Details of data used in this study.

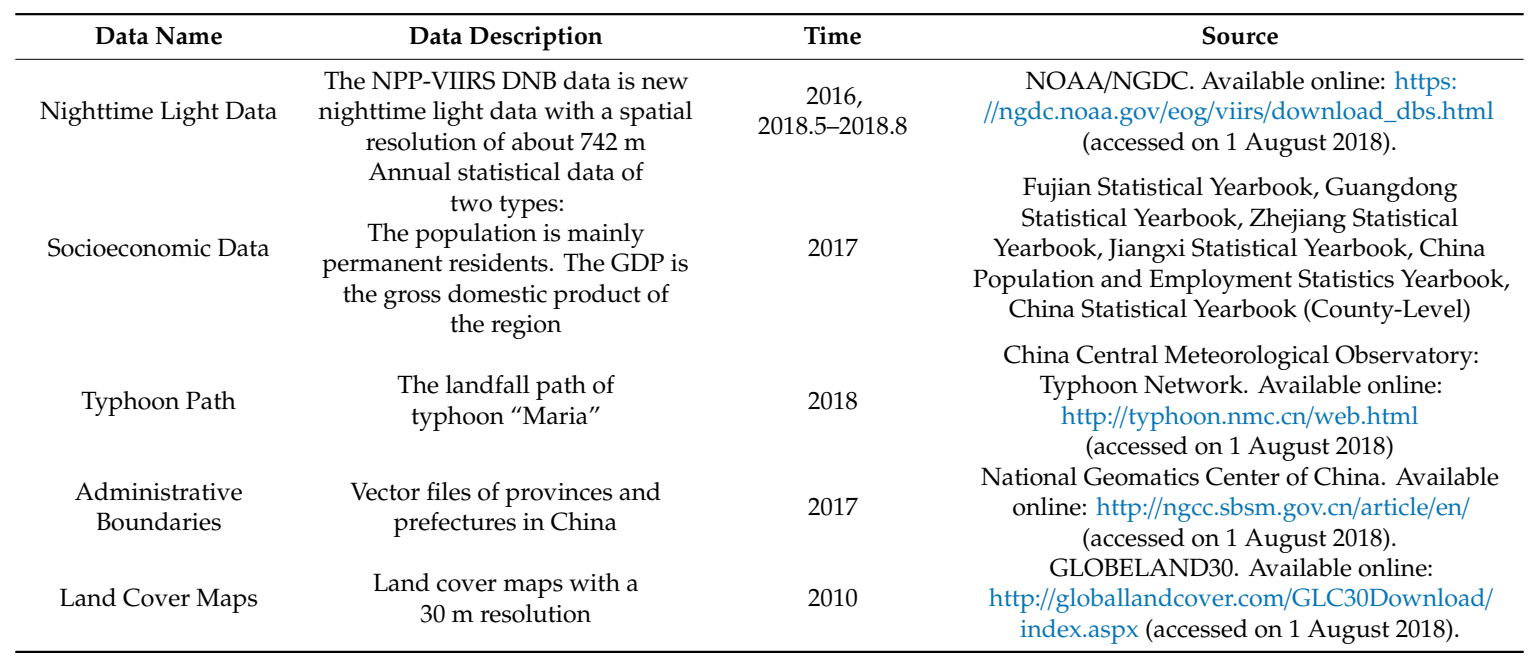




\subsection{Research Route}

In this study, the NTL data before and after the typhoon disaster were processed with geometric matching and image data normalization, which can help extract the unbiased information of land surface changes caused by the typhoon. The data also recorded the affected area and the degree of recovery. Using information regarding the population and GDP, we conducted correlation models between NTL data and population or GDP and used the best models from different scales. The models were used for quantitatively retrieving the population and GDP. Finally, the research identified the distribution of the affected area and estimated the affected area and affected the population. The information obtained was used to analyze the temporal-spatial distribution of the typhoon disaster and rapidly determined the degree of recovery. The result can provide supplementary data to support emergency rescue efforts and recovery assessment. The research process is outlined in Figure 2.

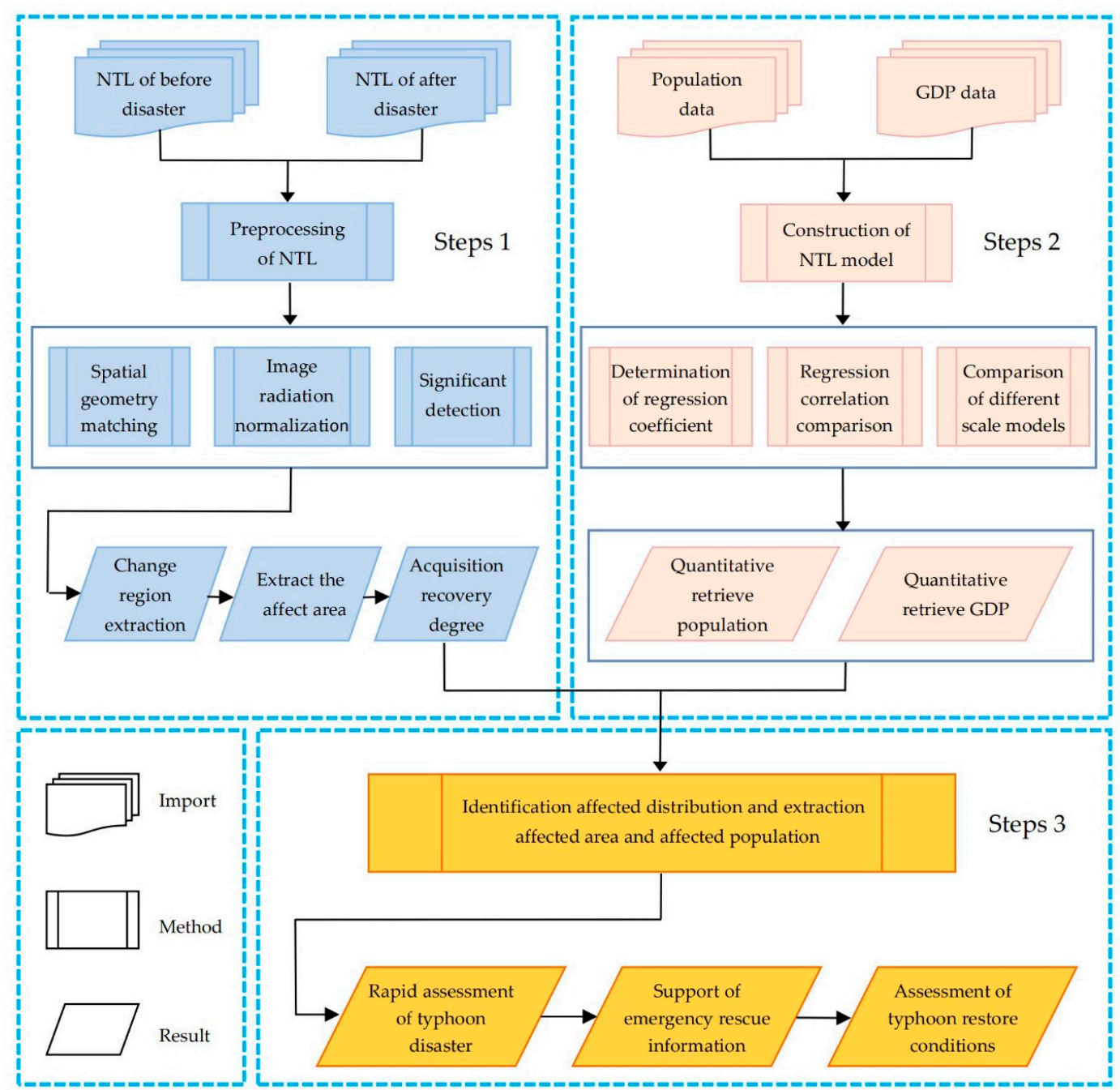

Figure 2. The outline of the research process.

\section{Methods}

\subsection{Data Pretreatment}

\subsubsection{Extraction of Change Region}

The NTL image represents the state of human activity. Under normal circumstances, the NTL in a given area is relatively stable over time (Figure 3a,b). After a strong typhoon disaster, the NTL intensity from the disaster area is generally weakened and the NTL from certain areas is even sharply reduced 
or completely disappears (Figure 3c). The changes in NTL caused by a strong typhoon disaster provide valuable information about the disaster, which can be extracted by detecting changes in NTL images before and after the typhoon disaster. At present, the commonly used methods to detect change via remote-sensing images are based on the pixel-difference method or the ratio method. Because of the low spatial resolution of NTL remote-sensing images and the obvious changes caused by typhoon disasters, we use the difference method in this research. The method can directly determine the area of change, avoid large-scale classification, and improve the detection efficiency [50,51].

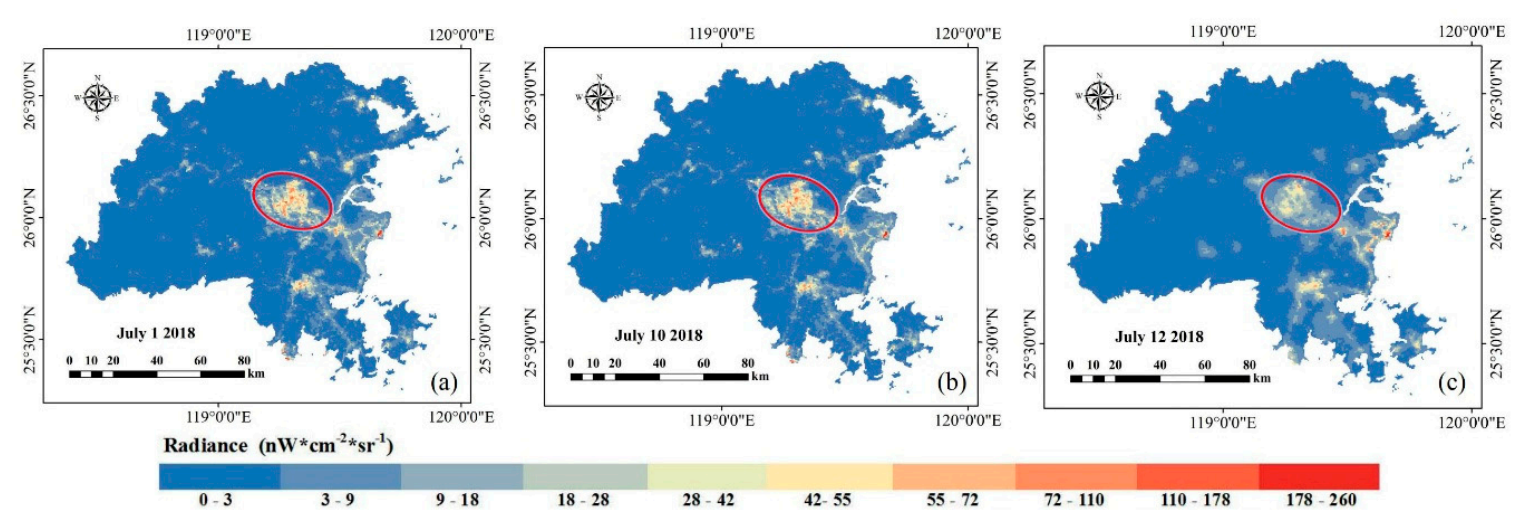

Figure 3. The nighttime light images before and after the strong typhoon Maria in Fuzhou: (a) Stable nighttime light before typhoon Maria, (b) constant nighttime light intensity before typhoon Maria, (c) the nighttime light intensity in middle areas was greatly reduced after typhoon Maria.

NTL data processing mainly consists of extracting regions where the image changes. Since the NPP-VIIRS DNB data are available daily, they contain inevitable noises, such as atmospheric clouds, flare points, and moonlight. Firstly, radiation normalization was applied to the multi-temporal images in the research region before and after the disaster. Relative radiation was normalized to minimize the radiation difference generated by different multi-temporal imaging conditions and sensor radiation differences $[52,53]$. The goal was to make the same feature ware fond of reflectivity for equal or similar values in the multi-temporal remote sensing images. The procedure involved the selection of a clear image a reference and normalizing the radiation values of other images by using the relationship between their pixel gray values and the reference image, resulting in the same radiation scale between the target images and the reference image [54]. Relative radiation normalization cannot only correct the differences caused by changes in atmospheric conditions but also reduce the noise generated by sensors and other sources [55].

Statistical radiation-normalization mainly uses a statistical characteristic quantity, such as gray mean, standard deviation and gray variation in the different-temporal images [56]. From the perspective of statistics, we find the same gray probability distribution in the remote-sensing images of a given region with the same radiation characteristics. This is due to the internal correlation of images, where images with the same gray probability distribution also have similar radiation characteristics. Therefore, the radiation normalization can be matched based on the statistics of the gray-scale probability distribution between images [57-59]. It is assumed that the image grayscale obeys Gaussian distribution [57]. Therefore, the following can be obtained:

$$
\frac{g_{d}-\mu_{f}}{\sigma_{f}}=\frac{g_{r}-\mu_{r}}{\sigma_{r}}
$$

where, $g_{d}$ is the pixel gray value after normalization of the original image, and $\mu_{f}$ and $\sigma_{f}$ are the pixel mean and standard deviation of the reference image, respectively, $g_{r}, \mu_{r}$ and $\sigma_{r}$ are the pixel gray value, mean value, and standard deviation of the original image, respectively. Transforming Equation (1), the statistics radiation-normalization model is derived as follows:

$$
g_{d}=\frac{g_{r}-\mu_{r}}{\sigma_{r}} \times \sigma_{f}+\mu_{f}
$$


Equation (2) is the statistics radiation-normalization equation [60]. As a linear transformation, it has been applied to environmental monitoring and natural disaster assessment [61]. Based on this method, Zhang et al. [59] successfully detected severe regions of earthquake damage based on NTL image data before and after an earthquake disaster, which was consistent with the research results extracted by Kohiyama et al. [32].

In this paper, stable composite images of two months before a typhoon disaster were used as reference images. After statistical radiation-normalization, the root-mean-square error of corrected images and reference images was reduced, indicating that statistical radiation-normalization method can effectively reduce the difference in radiation values between the target images and the reference images, and can effectively remove noise [62].

Secondly, the image difference method based on a significance test was used to extract the changed areas in this study. The image difference method was used to subtract the gray values of two temporal remote sensing images. The principle is that the non-affected areas generally have the same or similar gray values in the two temporal remote sensing images, while the gray values of the corresponding positions will be greatly different when the regions undergo changes. Therefore, the pixel value is close to zero in the area where no change occurs, so that the change information is shown in the background image [51]. The procedure involved the following steps:

Step 1: After the radiation normalization of the original image, the difference values in the image before and after the typhoon disaster can be calculated according to the image difference method. The stable composite images of two months before the typhoon were selected as the data before the typhoon, and then the daily image data for each city of study after the typhoon and the image data before the typhoon were calculated, respectively, for calculating the difference image.

Step 2: Since the difference images of multi-temporal images before and after the typhoon disaster satisfies the normal distribution [57], the Gaussian distribution function can be calculated according to the values of the difference images, as shown in Equation (3):

$$
g=\frac{1}{\sqrt{2 \pi} \cdot \sigma} e^{\frac{-(x-\mu)^{2}}{\sigma^{2}}}
$$

Step 3: Based on the obtained Gaussian density function, the rationality of the significance test was analyzed by using a Gaussian fitting probability distribution function. The segmentation threshold of the significance test was calculated for the difference value images based on Gaussian distribution and significance levels (95\%), which could avoid the randomness of an artificial threshold [63].

Step 4: The radiation of a post-event for the typhoon disaster on a pixel basis was examined by using a significance test of a Gaussian distribution. According to the calculated threshold, the pixel area of affected change was extracted from the difference image.

\subsubsection{Significance Test}

In the significance test, once the probability density function and the confidence are determined, the independent variable of the probability density function can be determined. In this research, the independent variable is the difference between the images before and after the typhoon disaster. Because the resolution of the NTL remote-sensing image is low, and the weather introduces significant noise into the image, the significance levels are set to $95 \%$, which does not lead to excessive false alarms or missed detections $[32,64]$. The difference image is the image obtained by subtracting the post-disaster image from the pre-disaster image. Because the brightness of the NTL is reduced after the disaster, the pixels of the difference image are basically greater than zero, and the change region mainly reflects the areas with positive pixel values. 


\subsection{Model Development}

\subsubsection{NTL Image Derivatives and Socio-economic Indices}

For a given region, we considered five NTL imagery derivatives, light density (LD), total light (TL), light area (LA), weighted light density (WLD), and total weighted light (TWL). These indicators are calculated with Equations (4)-(8).

$$
\begin{gathered}
\mathrm{LD}=\frac{\sum D N_{i}}{A} \\
\mathrm{TL}=\sum D N_{i} \\
\mathrm{LA}=\sum i, D N_{i}>1 \\
\mathrm{WLD}=\alpha \cdot \frac{\sum D N_{i}}{N}+\beta \cdot \sum i\left(D N_{i}>1\right) \\
\mathrm{TWL}=\alpha \cdot \sum D N_{i}+\beta \cdot \sum i(D N>1)
\end{gathered}
$$

where, $\mathrm{DN}$ is digital numbers, $A$ is area, $\alpha=0.8$ and $\beta=0.2$ [65].

The socio-economic indices included population density (PD), total population (TP) and GDP in this study. We used each socioeconomic index as a dependent variable and each NTL imagery derivative as an independent variable to perform regression analysis.

\subsubsection{Linear Regression Models}

A number of models, including linear regression models [14,42,66], log-log regression models [67], and second-order regression models [68], have been used to estimate population and GDP using NTL data. Among these options, linear regression models are relatively accurate and easy to implement. Linear regression models [14,42] were used in this research. The regression analysis was made at the prefecture level and county level, respectively. Mathematically, the general regression model is expressed as follows:

$$
Y_{i}=k_{i} \cdot X_{i}+b_{i}
$$

where, $Y_{i}$ represents PD, TP or GDP, $X_{i}$ represents LD, TL, LA, WLD, or TWL, $k_{i}$ is slope, and $b_{i}$ is intercept.

\subsubsection{Determination of the Affected Area and Affected Population}

First, the NTL image data were projected into an Asia North Albers Equal Area Conic, and the raster data were resampled to $500 \mathrm{~m}$. After radiation normalization, the change region of the image in different time phases was calculated under the significance verification, which was the affected area. Second, using spatial analysis, the intensity and area of the pixel values of the NTL images in each region were calculated. Combined with the relationship constructed between the NTL image and the population (Equation (9)), the population density of the affected area was calculated from the NTL density of the affected area. Finally, according to the population density of the affected area and the affected area itself, the total affected population was computed as

$$
P_{E}=\rho_{E} \cdot A_{E}
$$

where, $P_{E}$ is the total population affected, $\rho_{E}$ is the population density in the affected area, and $A_{E}$ is the affected area. 
In addition, the fraction of the affected area and the affected population was obtained by using the total geographical area and the total population in each city.

\subsubsection{Precision Evaluation of Retrieve Results}

Through the regression model constructed for the research area, we obtained the NTL retrieve population and GDP data. At the same time, the method proposed to calculate the affected population could be used to retrieve the affected population in the study area based on the NTL data. The accuracy of the TNL predicted population, GDP, and the affected population was expressed with the relative error:

$$
e=\frac{p-r}{r}
$$

where, $e$ is the relative error, $p$ is the predicted value, and $r$ is the true value [16].

\subsubsection{Assessment Method for Affected Intensity}

In the post-disaster assessment, the affected intensity refers to the ratio of the total amount of NTL radiation post-disaster to the same quantity pre-disaster $[33,37,38]$. This ratio is called the proportion of NTL (PNL):

$$
\mathrm{PNL}=\frac{N T L_{\text {post-disaster }}}{N T L_{\text {pre-disaster }}}
$$

where, $N T L_{\text {post-disaster }}$ is the total NTL radiation after a disaster, and $N T L_{\text {pre-disaster }}$ is the total NTL radiation before a disaster. As shown by Equation (12), a smaller PNL reflects a greater decrease in the total NTL intensity after the disaster.

\section{Results}

\subsection{Relationship between NTL Data and Population or GDP}

\subsubsection{Linear Regression}

In this study, various linear regression models were developed between different NTL indexes with population and GDP, which were used to fully confirm the best linear regression model between NTL data and population or GDP in a region. At the county level, the LD and PD had a stronger regression $\left(R^{2}=0.80\right)$ than the other three combinations (Figure 4a-d). The $R^{2}$ values between GDP and TL are greater than LD (Figure 4e,f). The correlations between the NTL area with population and GDP in the county regions seemed not strong as their $\mathrm{R}^{2}$ values were all below 0.5 (Figure 5). There were stronger correlations between WLD vs. PD $\left(R^{2}=0.79\right)$, between TWL and GDP $\left(R^{2}=0.71\right)$ than the other four combinations (Figure 6). 

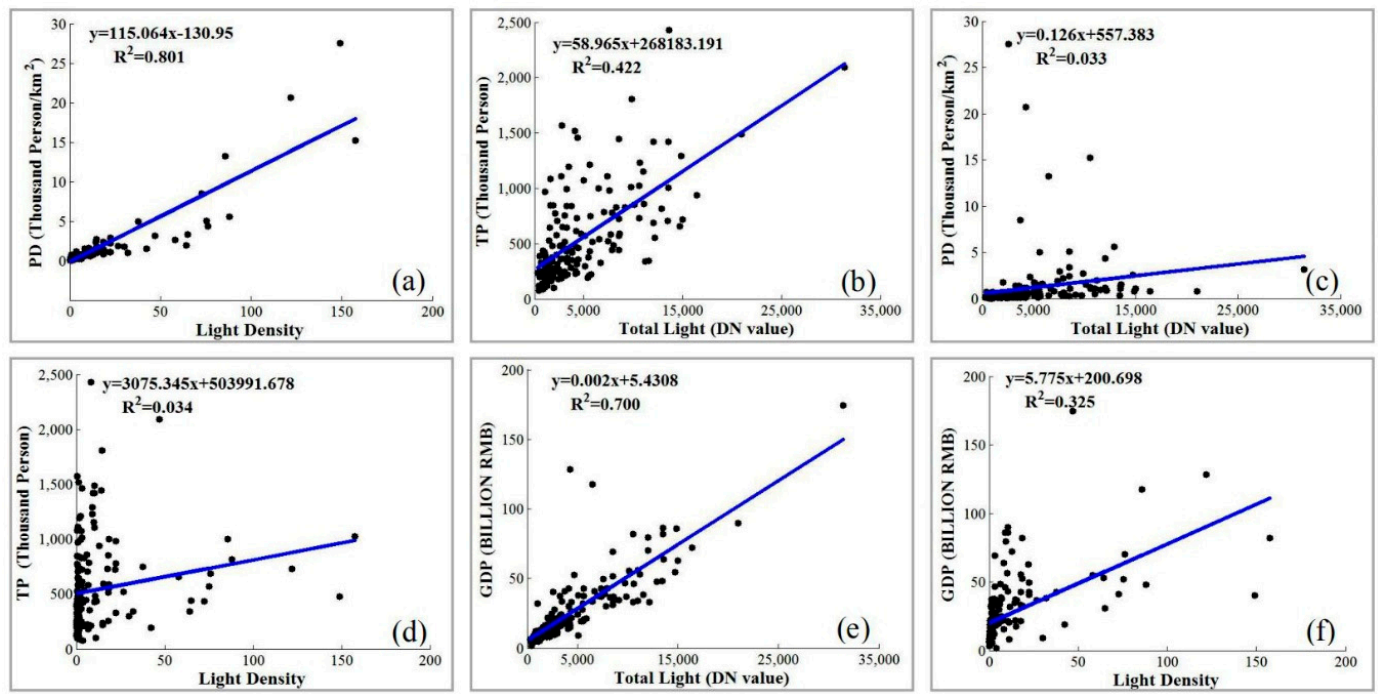

Figure 4. Regression model of between nighttime light (NTL) intensity and population or gross domestic product (GDP): (a) Light density versus population density (PD), (b) total light versus total population (TP), (c) total light versus $\mathrm{PD}$, (d) light density versus TP, (e) total light versus GDP, (f) light density versus GDP.
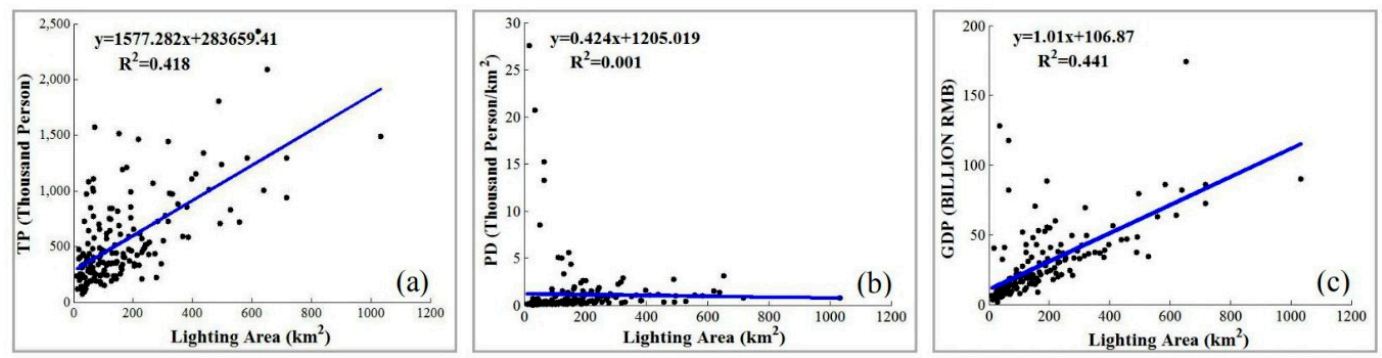

Figure 5. Regression model between NTL area and population or GDP: (a) Light area versus total population (TP), (b) light area versus population density (PD), (c) light area versus GDP.
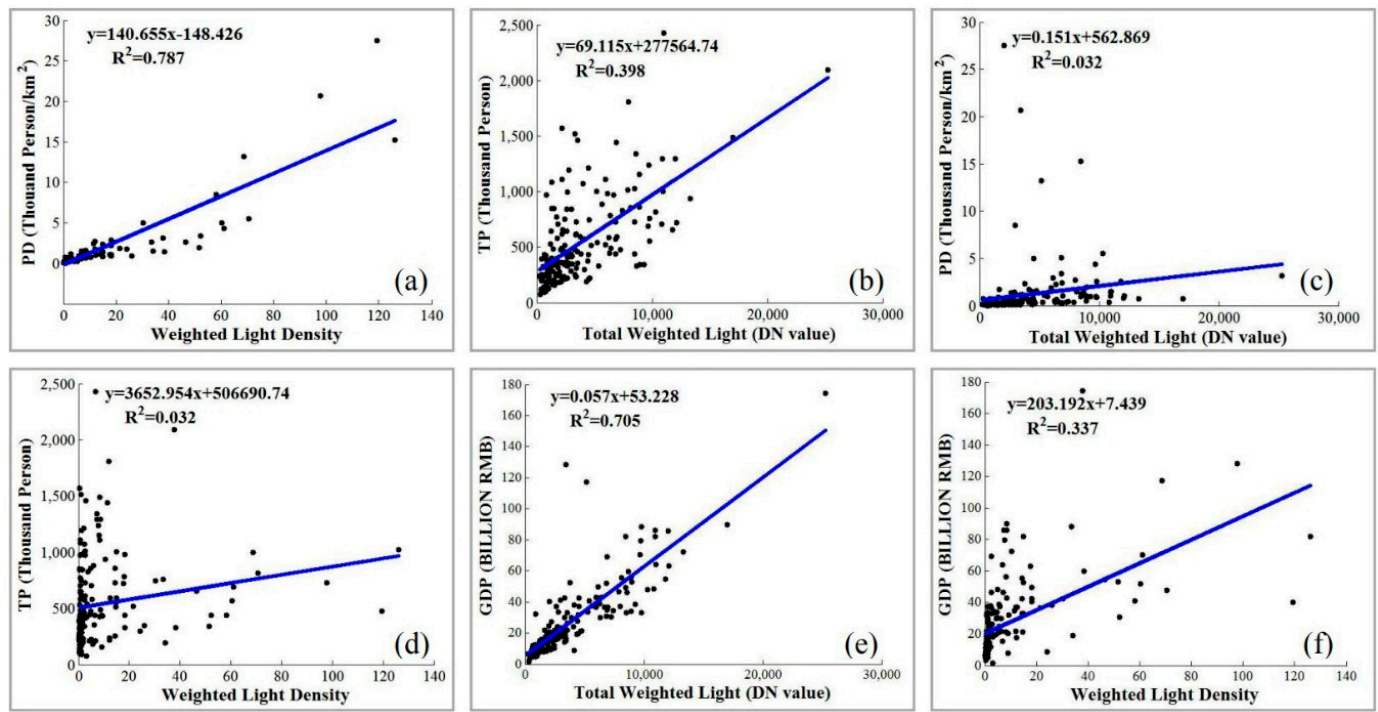

Figure 6. Regression model between weighted NTL intensity and population or GDP: (a) Weighted light density versus population density (PD), (b) total weighted light versus total population (TP), (c) total weighted light versus PD, (d) weighted light density versus TP, (e) total weighted light versus GDP, (f) weighted light density versus GDP. 
At the prefecture-level scale, in the NTL-intensity regression model, the $\mathrm{R}^{2}$ of PD vs. LD is 0.83 , and they possess the strongest correlation, the $\mathrm{R}^{2}$ of TP vs. TL is 0.51 , and their correlation is average, the correlation between PD and TL is basically negligible $\left(R^{2}=0.12\right)$ (Figure 7). The worst correlation is observed between TP and LD. The $\mathrm{R}^{2}$ of GDP with TL is as high as 0.96 , indicating the strongest correlation. The $\mathrm{R}^{2}$ of GDP vs. LD is only 0.14 .

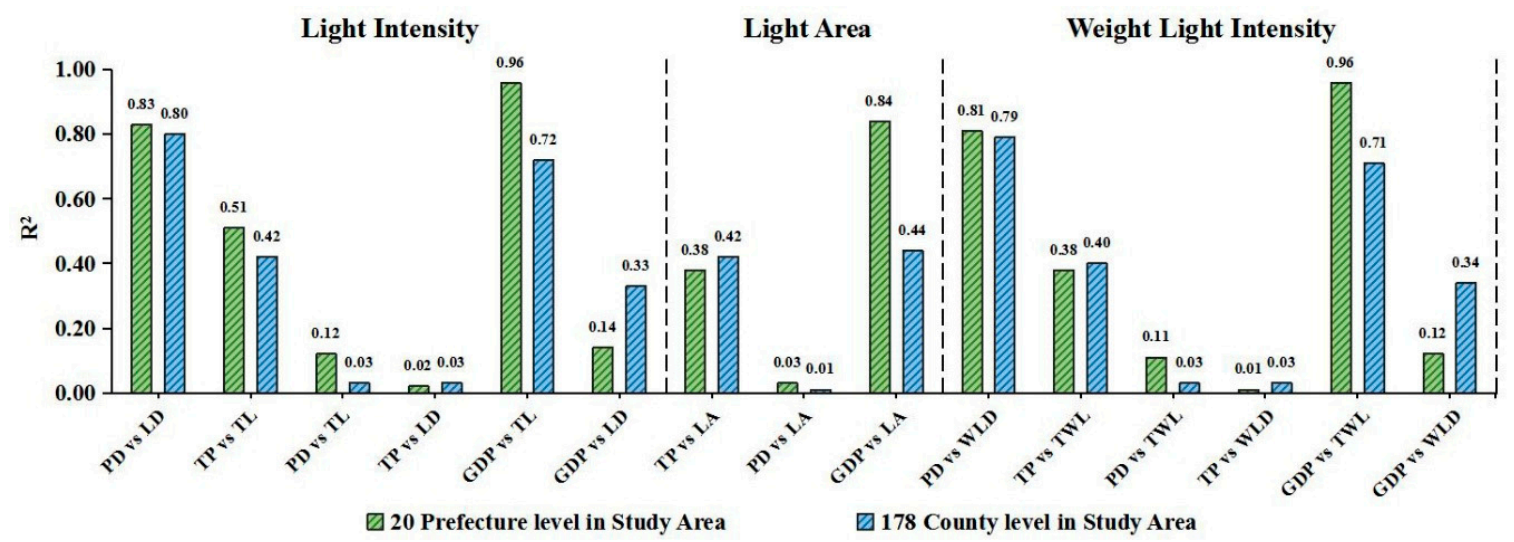

Figure 7. The $\mathrm{R}^{2}$ values for correlations between NTL indicators and population or GDP at the prefecture level and county level.

In the NTL-area model, the correlation between LA and TP or PD is weak, but LA has a certain correlation with GDP $\left(R^{2}=0.84\right)$. In the weighted NTL -intensity model, the $R^{2}$ of PD vs. WLD is 0.81 . The $\mathrm{R}^{2}$ of TP with total weighted light (TWL) is only 0.38. TP is basically irrelevant to WLD $\left(\mathrm{R}^{2}=0.01\right)$, However, the correlation of GDP vs. TWL is quite strong $\left(R^{2}=0.96\right)$. The correlation between GDP and WLD is unclear $\left(R^{2}=0.12\right)$.

As shown in Figure 7, the correlation at the prefecture level is greater than at the county level for PD vs. LD, GDP vs. TL, PD vs. WLD, and GDP vs. TWL.

The above three regression models of NTL intensity, NTL area, and weighted NTL intensity lead to the following findings:

(1) In the relationship between NTL and population, the NTL density and weighted NTL density in each region are strongly correlated with the population density, whereas the NTL area is weakly correlated or not correlated with the total population and population density.

(2) In the relationship between NTL and GDP, the total NTL is strongly correlated with the total GDP, the correlation between the NTL area and GDP is less strong, and the correlation between NTL density and GDP is weak.

(3) The intensity and area of NTL theoretically reflect population aggregation and economic development from different viewpoints. However, the construction of NTL indicators needs to be adapted to local conditions. The weight of indexes will affect the correlation in different regions, and the coefficient setting should be selected according to the actual empirical value.

Finally, in the relationship between NTL Data and population data, the correlation between NTL density and population density is the strongest, with $\mathrm{R}^{2}$ value of 0.83 . In the relationship between NTL Data and GDP data, the correlation between total NTL intensity and total GDP is the strongest, with $\mathrm{R}^{2}$ value of 0.96 . Therefore, this study uses the regression model between nighttime intensity and population density to retrieve population and adopts the regression model between total NTL intensity and total GDP to retrieve GDP.

\subsubsection{Accuracy of NTL Data for Retrieving Population and GDP}

To accurately reflect the population and GDP distribution before the typhoon disaster, the above regression results show that the NTL density has the strongest correlation with the population density, 
and the total NTL intensity has the strongest correlation with total GDP. According to Equation (9), different regression models between NTL and population or GDP can be constructed. Functions are fit to the data from the different regions, and the resulting regression coefficients are given in Table A1.

The regression analysis shows that the NPP-VIIRS DNB image has a strong capacity to determine the population and GDP, and the relative error can be used to estimate the accuracy of the NTL data for predicting the population and GDP. First, we obtained the real values for the population and GDP for 20 prefecture-level scales in the research area in 2016. Then, we quantitatively estimated the total population and GDP of each city by choosing the prefecture fitting function and then obtain the relative error of the NTL for predicting the population and GDP for the 20 cities (Table 2). Since there are 178 counties in the research area, we only show the overall accuracy of the situation in Table 3.

Table 2. Difference between real data and predicted values for population (thousand) and GDP (billion $\mathrm{RMB}$ ) from NPP-VIIRS data in prefecture regions. RD is real data, PD is predicted data, and RE is relative error.

\begin{tabular}{ccccccc}
\hline \multirow{2}{*}{ Region } & \multicolumn{3}{c}{$\begin{array}{c}\text { Population and Prediction from } \\
\text { NPP-VIIRS Nighttime Light Data }\end{array}$} & \multicolumn{2}{c}{$\begin{array}{c}\text { GDP And Prediction From NPP-VIIRS } \\
\text { Nighttime Light Data }\end{array}$} \\
\cline { 2 - 7 } & RD & PD & RE & RD & PD & RE \\
\hline Caozhou & 2646 & 2053 & -0.22 & 101.64 & 152.22 & 0.50 \\
Fowchow & 4011 & 4874 & 0.22 & 121.56 & 98.70 & -0.19 \\
Fuzhou & 7570 & 8808 & 0.16 & 619.76 & 541.85 & -0.13 \\
Ganzhou & 8589 & 10402 & 0.21 & 219.23 & 188.49 & -0.14 \\
Jieyang & 6094 & 3058 & -0.50 & 206.12 & 217.45 & 0.05 \\
Lishui & 2680 & 4534 & 0.69 & 120.02 & 151.99 & 0.27 \\
Longyan & 2630 & 3977 & 0.51 & 189.57 & 142.16 & -0.25 \\
Meizhou & 4361 & 4894 & 0.12 & 104.56 & 127.47 & 0.22 \\
Nanping & 2660 & 4239 & 0.59 & 145.77 & 126.65 & -0.13 \\
Ningde & 2890 & 3562 & 0.23 & 162.31 & 166.10 & 0.02 \\
Putian & 2890 & 3438 & 0.19 & 182.34 & 252.05 & 0.38 \\
Quanzhou & 8580 & 9979 & 0.16 & 664.66 & 653.63 & -0.02 \\
Quzhou & 2575 & 3138 & 0.22 & 125.16 & 125.04 & 0.00 \\
Sanming & 2550 & 4615 & 0.81 & 186.08 & 125.30 & -0.33 \\
Shangrao & 6752 & 6465 & -0.04 & 181.78 & 117.29 & -0.35 \\
Shantou & 5579 & 3469 & -0.38 & 198.68 & 275.41 & 0.39 \\
Wenzhou & 8182 & 8302 & 0.01 & 510.16 & 501.50 & -0.02 \\
Xiamen & 3920 & 4705 & 0.20 & 348.43 & 406.44 & 0.17 \\
Yingtan & 1159 & 1185 & 0.02 & 71.35 & 70.24 & -0.02 \\
Zhangzhou & 5050 & 6468 & 0.28 & 312.54 & 326.45 & 0.04 \\
Average & - & - & 0.175 & - & - & 0.024 \\
\hline
\end{tabular}

Table 3. Percent relative error for retrieving population and GDP by using different fitting functions at different scales.

\begin{tabular}{|c|c|c|c|c|c|c|c|}
\hline \multirow{2}{*}{$\begin{array}{l}\text { Region } \\
\text { and Data }\end{array}$} & \multirow{2}{*}{$\begin{array}{l}\text { Fitting } \\
\text { Function }\end{array}$} & \multicolumn{3}{|c|}{ NPP-VIIRS Data vs. Population } & \multicolumn{3}{|c|}{ NPP-VIIRS Data vs. GDP } \\
\hline & & $\begin{array}{c}\text { High } \\
\text { Accuracy }\end{array}$ & $\begin{array}{l}\text { Moderate } \\
\text { Accuracy }\end{array}$ & Inaccurate & $\begin{array}{c}\text { High } \\
\text { Accuracy }\end{array}$ & $\begin{array}{l}\text { Moderate } \\
\text { Accuracy }\end{array}$ & Inaccurate \\
\hline \multirow{2}{*}{$\begin{array}{l}\text { Prefecture } \\
\text { regions }\end{array}$} & Prefecture & 65 & 10 & 25 & 70 & 30 & 0 \\
\hline & $\begin{array}{l}\text { Partition } \\
\text { prefecture }\end{array}$ & 35 & 35 & 30 & 90 & 10 & 0 \\
\hline \multirow{4}{*}{$\begin{array}{l}\text { County } \\
\text { regions }\end{array}$} & County & 15 & 25 & 60 & 70 & 25 & 5 \\
\hline & Prefecture & 34.5 & 23.7 & 41.8 & 19.8 & 27.1 & 53.1 \\
\hline & $\begin{array}{l}\text { Partition } \\
\text { prefecture }\end{array}$ & 31.6 & 26 & 42.4 & 6.2 & 3.4 & 90.4 \\
\hline & County & 14.2 & 12.4 & 73.4 & 55.4 & 27.7 & 16.9 \\
\hline
\end{tabular}


Table 2 shows that the accuracy differs for determining the population and GDP of cities with different economic development levels. The maximum and minimum relative error for determining prefecture-level population from NPP-VIIRS data is $81 \%$ and $1.5 \%$, respectively, and the maximum and minimum relative error for determining the prefecture-level GDP by NPP-VIIRS data is $49.8 \%$ and $0.1 \%$, respectively. At the same time, the average relative error for determining population and GDP from NPP-VIIRS data is $17.5 \%$ and $2.4 \%$, respectively. The NPP-VIIRS data can predict GDP more accurately than the population.

In addition, the results show that NPP-VIIRS data are overestimated in underdeveloped areas (such as Sanming city and Lishui city), whereas developed areas (such as Shantou city and Jieyang city) are underestimated. For example, the relative errors for Sanming city and Lishui City are $81 \%$ and $69 \%$, respectively. In the predicted population, the retrieval results are larger than the actual results. On the contrary, the relative error for Shantou city and Jieyang city is $-38 \%$ and $-50 \%$, respectively, which means that the predicted results are lower than the actual results. A similar phenomenon also occurs for determining GDP from NPP-VIIRS data. To explore this phenomenon, we compare the relative error between the population density of 20 cities in the district with the relative error of the predicted population and find a correlation coefficient of -0.439 at a significance level of 0.005 . The correlation coefficient between the per capita GDP of 20 cities with the relative error of retrieval GDP is -0.251 . These results indicate that the relative error has a significantly negative correlation with the population density and per capita GDP. Therefore, when using this regression model to evaluate certain parameters, it is necessary to pay attention to the overestimation and underestimation in regions with different economic development levels.

In the quantitative retrieval of population and GDP from NTL data, the same model leads to different accuracies for the retrieval results in different scale areas. The administrative divisions in mainland China are divided into five levels: Province, prefecture city, county, town, and village. The population and GDP data for town and village level are relatively imperfect, and only Fujian province is a totally provincial administrative region. Therefore, this module uses prefecture-level and county-level scales to verify the accuracy of the retrieval results for different fitting models applied to different scales. To better verify the accuracy of the NTL data retrieval, we follow the research of $\mathrm{Li}$ et al. [16] by assigning three levels to the accuracy of Equation (11) for calculating the retrieval results: $0 \%-25 \%$ is high precision, $25 \%-50 \%$ is medium precision, and greater than $50 \%$ is an error. High precision and medium precision are defined as accurate retrieval. Next, we calculate the percent difference between the fitting function and the data at the various levels. For example, when estimating the prefecture-level population from NPP-VIIRS data, the population of 13 out of 20 cities is retrieved with high accuracy, which gives $65 \%$ high accuracy for retrieving the prefecture-level population. Table 3 shows the accuracy of population retrieval and GDP for each fitting method for the prefecture and county scales.

Table 3 shows that: (1) For the retrieved population, at the prefecture-level and county scales, the retrieval accuracy of the prefecture-level fitting function is better, with accuracy rates of $75 \%$ and $58.2 \%$, respectively. (2) For the retrieved GDP, at the prefecture-level scale, the classification of the prefecture-level fitting function is the most accurate, with an accuracy rate as high as $100 \%$. At the county-level scale, the accuracy of the county-level fitting function is higher (83.1\%). (3) Comparing the prefecture-level and county-level scales shows that the three retrieval models are used to retrieve the population and GDP, whose retrieval results at prefecture level are better than that at county level. The results demonstrate that, to a certain extent, the retrieved GDP is better than the retrieved population from NTL data, and the correlation between NTL with GDP is stronger. The accuracy of the population and GDP retrieved from the NTL data is higher at prefecture-level than at the county-level. At the same time, the correlation of the retrieval of the prefecture-level population and GDP is the best when using the prefecture-level fitted function models. Therefore, we use the prefecture-level scales to extract disaster information and quickly assess areas subjected to typhoons. 


\subsection{Estimates of Affected Area and Affected Population Retrieved from NTL Data}

\subsubsection{Distribution of Affected Areas in Study Area}

As per the calculation method used in this research, the research area was divided into 20 cities according to the prefecture level. Several small areas that were not affected by cloud layer and noise were selected as statistical samples in each city. Mean and variance for samples of the NTL image of each city were calculated separately. For each sample from the 20 cities, the statistical parameters for normalized radiation were calculated (see Table A2). After the typhoon disaster, the affected areas and the specific distribution of each city were calculated (see Figure 8a). At the same time, based on the relationship between the stable yearly NTL images for the research area in 2016 and the population density in 2016, the quantitative population density in 2018 was retrieved from the NTL images in 2018 and interpolated, and the results were superimposed onto the retrieved distribution map of the typhoon-affected areas (see Figure 8 b). The extracted areas of impact were mainly concentrated in the densely populated areas along the eastern coast of the research area and in the built-up areas of inland cities.
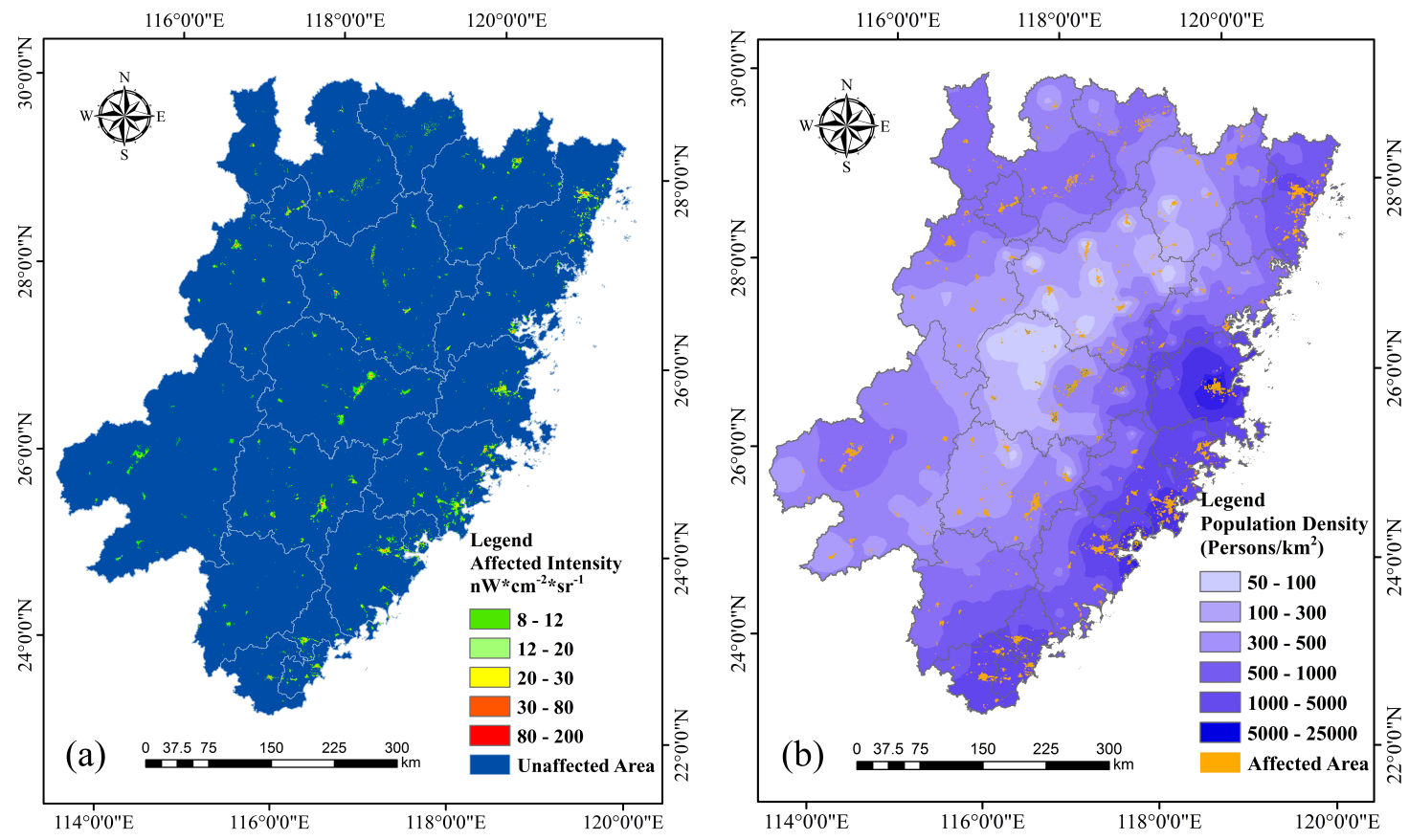

Figure 8. Affected areas after the typhoon disaster in the research area: (a) Distribution of affected areas, (b) superposition of affected areas and population density.

\subsubsection{Estimate Affected Area and Affected Population}

The overall statistical situation shows that the affected area covers $4951.25 \mathrm{~km}^{2}$, which accounts for $1.83 \%$ of the total research area (Table 4 ). The total affected population in the research area is $1,423,355$, which is $1.56 \%$ of the total population in the research area. According to the calculation, the affected population according to the NPP-VIIRS DNB image retrieval was 212,065 people in Ningde City. According to news reports, Typhoon Maria affected 248,885 people in Ningde City [69], so the retrieval accuracy is $85.21 \%$. According to retrieval from the NPP-VIIRS DNB images, the total population in the nine cities of Fujian Province was 639,868. According to a news report, 762,500 people were affected in Fujian Province [70], so the accuracy rate for retrieving the affected population in Fujian Province is $83.92 \%$. In addition, the NPP-VIIRS DNB image retrieval gives the total population affected as 1,423,355 in the research area. According to previous research [71], the population affected was $1,218,200$, these were from the literature and were fond of reference value, Thus, the accuracy rate is $83.16 \%$. The retrieval accuracy determined by news report data is close to that determined by previous 
research results [71]. Therefore, the overlapping reference data between the two sources above were consistent. The comparison of the retrieval results for the affected population with the actual statistical data shows that the retrieval accuracy is reliable. Therefore, the method for retrieving the affected population is accurate and feasible.

Table 4. Area and population affected by typhoon based on NTL image retrieval.

\begin{tabular}{|c|c|c|c|c|c|c|c|}
\hline Region & $\begin{array}{c}\text { Total } \\
\text { Prefecture } \\
\text { City Area } \\
\left(\mathbf{k m}^{2}\right)\end{array}$ & $\begin{array}{c}\text { Retrieval } \\
\text { Affected } \\
\text { Area } \\
\left(\mathbf{k m}^{\mathbf{2}} \mathbf{)}\right.\end{array}$ & $\begin{array}{l}\text { Percent of } \\
\text { Retrieval } \\
\text { Affected } \\
\text { Area (\%) }\end{array}$ & $\begin{array}{c}\text { Total } \\
\text { Population } \\
\text { (thousand } \\
\text { people) }\end{array}$ & $\begin{array}{l}\text { Affected } \\
\text { Population } \\
\text { Density } \\
\text { (people/ } \\
\text { km }^{2} \text { ) }\end{array}$ & $\begin{array}{c}\text { Retrieval } \\
\text { Affected } \\
\text { People } \\
\text { (people) }\end{array}$ & $\begin{array}{l}\text { Percent of } \\
\text { Retrieval } \\
\text { Affected } \\
\text { Population } \\
(\%)\end{array}$ \\
\hline Caozhou & 3113.20 & 59.75 & 1.92 & 2,646 & 765.21 & 45,721 & 1.73 \\
\hline Fowchow & $18,801.22$ & 241.75 & 1.29 & 4,011 & 333.48 & 80,618 & 2.01 \\
\hline Fuzhou & $11,696.64$ & 221.50 & 1.89 & 7,570 & 314.69 & 69,704 & 0.92 \\
\hline Ganzhou & $39,363.55$ & 474.00 & 1.20 & 8,589 & 96.05 & 45,526 & 0.53 \\
\hline Jieyang & 5257.95 & 176.00 & 3.35 & 6,094 & 190.53 & 33,534 & 0.55 \\
\hline Lishui & $17,275.32$ & 269.25 & 1.56 & 2,680 & 306.81 & 82,609 & 3.08 \\
\hline Longyan & $19,025.94$ & 265.75 & 1.40 & 2,630 & 159.26 & 42,324 & 1.61 \\
\hline Meizhou & $15,864.50$ & 64.25 & 0.40 & 4,361 & 205.34 & 13,193 & 0.30 \\
\hline Nanping & $26,288.15$ & 383.25 & 1.46 & 2,660 & 192.95 & 73,947 & 2.78 \\
\hline Ningde & $13,048.93$ & 326.50 & 2.50 & 2,890 & 649.51 & 212,065 & 7.34 \\
\hline Putian & 3910.03 & 145.25 & 3.71 & 2,890 & 318.45 & 46,255 & 1.60 \\
\hline Quanzhou & $11,045.42$ & 312.75 & 2.83 & 8,580 & 225.09 & 70,396 & 0.82 \\
\hline Quzhou & 8843.66 & 222.25 & 2.51 & 2,575 & 231.82 & 51,521 & 2.00 \\
\hline Sanming & $22,963.87$ & 338.50 & 1.47 & 2,550 & 149.28 & 50,532 & 1.98 \\
\hline Shangrao & $22,743.76$ & 335.50 & 1.48 & 6,752 & 242.52 & 81,364 & 1.21 \\
\hline Shantou & 2176.70 & 122.25 & 5.62 & 5,579 & 561.00 & 68,582 & 1.23 \\
\hline Wenzhou & $11,597.82$ & 457.50 & 3.94 & 8,182 & 513.25 & 234,810 & 2.87 \\
\hline Xiamen & 1579.90 & 69.25 & 4.38 & 3,920 & 516.85 & 35,792 & 0.91 \\
\hline Yingtan & 3557.87 & 93.25 & 2.62 & 1,159 & 493.09 & 45,981 & 3.97 \\
\hline Zhangzhou & $12,620.59$ & 372.75 & 2.95 & 5,050 & 104.31 & 38,881 & 0.77 \\
\hline
\end{tabular}

At present, no report or archived data sources exist concerning the affected area. However, because the affected population is calculated and obtained based on the affected area (see Equation (10)), the affected area retrieved also be accurate. As shown by Table 4, Wenzhou city has the largest affected area of $457.50 \mathrm{~km}^{2}$ and Chaozhou city has the smallest affected area of $59.75 \mathrm{~km}^{2}$. The affected population reached 855,740 in the eastern region of the research area, accounting for $60.12 \%$ of the total affected population, while the total area of 10 cities in the eastern region only accounts for $26.14 \%$ of the research area. The distribution of the affected population in Figure 9a shows that the eastern part is more affected than the western part, and the northern part is more affected than the southern part, and the most affected population is in Wenzhou City, which is consistent with the news reports after the disaster.

\subsubsection{Assessment based on Affected Intensity}

First, the ratio of NTL intensity for the affected intensity in each city is calculated by using the PNL calculation. Next, based on the relationship between stable composite NTL images in 2016 and GDP in 2016, the quantitative GDP of each city in 2018 is retrieved by using composite NTL images from 2018, in units of billions of yuan. Finally, the two results are superimposed, as shown in Figure 9b. There are eleven major affected cities (PNL $<80 \%$ ) in the eastern part of the research area, accounting for $69.84 \%$ of the total affected intensity. The smaller affected cities (PNL $>80 \%$ ) consisted of a total nine cities in the western part of the research area, accounting for $30.16 \%$ of the total affected intensity. In conclusion, the eastern cities in the research area were clearly affected, whereas the western cities 
were not clearly affected. This result is closely related to the dense population and high level of economic development in the eastern cities.
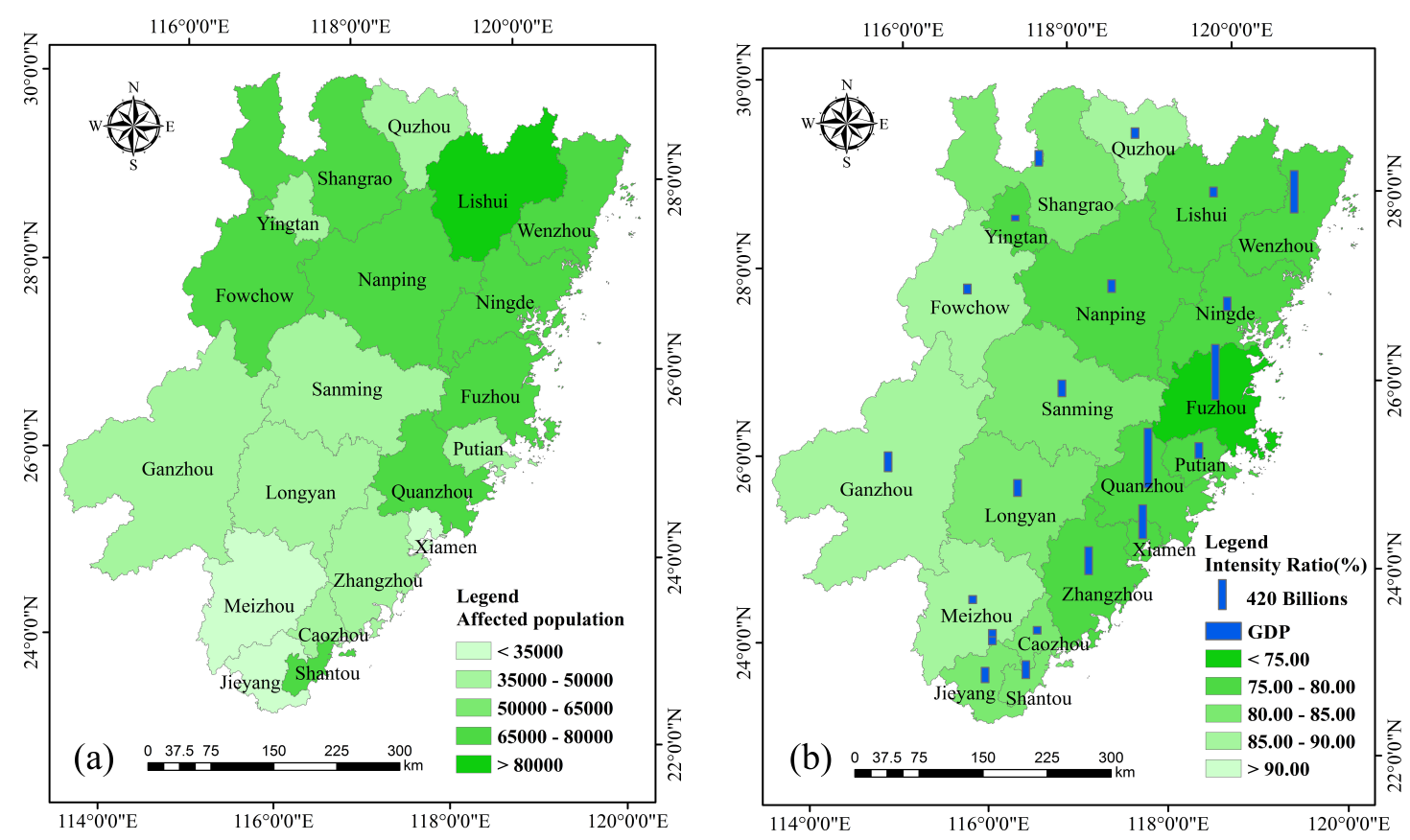

Figure 9. Assessment of affected population and affected intensity: (a) Distribution of affected population, (b) superposition of percent of normal light (PNL) and GDP.

\subsection{Disaster Recovery Assessment based on NTL Data Retrieval}

\subsubsection{Assessment of Daily Affected Area Based on NTL Data Retrieval}

The affected area determined from NTL image retrieval can be used to assess the post-disaster recovery. According to the NTL image retrieval, the total affected area was $4951.25 \mathrm{~km}^{2}$ on the first day after Maria (12 July, 2018), accounting for $1.83 \%$ of the total research area. The total affected area was $3240.25 \mathrm{~km}^{2}$ one week after Maria (18 July, 2018), of which $30.92 \%$ had been restored. The total affected area was $2474.00 \mathrm{~km}^{2}$ two weeks after Maria (25 July, 2018), of which $50.03 \%$ had been restored. The total affected area was $648.75 \mathrm{~km}^{2}$ three weeks after Maria (1 August, 2018), of which $86.90 \%$ had been restored, accounting for only $0.23 \%$ of the total research area, as shown in Figure 10.

Two weeks after the disaster, the affected area recovered by more than $50 \%$, which shows that the affected area was continually recovering. Three weeks after the disaster, the affected area of most cities was less than $50 \mathrm{~km}^{2}$, which indicates that the affected area is greatly reduced by this time. By retrieving and calculating the daily affected area, we can analyze the temporal-spatial distribution of typhoon disasters and rapidly estimate the degree of recovery on a macro scale. At the same time, the cities in Wenzhou, Ningde, Fuzhou, Quanzhou, Zhangzhou, and so on, in the eastern part of the research area recovered rapidly. The cities of Nanping, Shangrao, Sanming, and Longyan, were more seriously affected and the recovery was more evident. However, the recovery of the western cities in the research area, such as Fowchow, Ganzhou, Yingtan, and Jieyang, recovered more slowly. In a word, the eastern cities recovered more quickly after the disaster, whereas the western cities recovered slowly, likely because the coastal cities in the eastern part of research area are more developed and the urban infrastructure is more modern. 


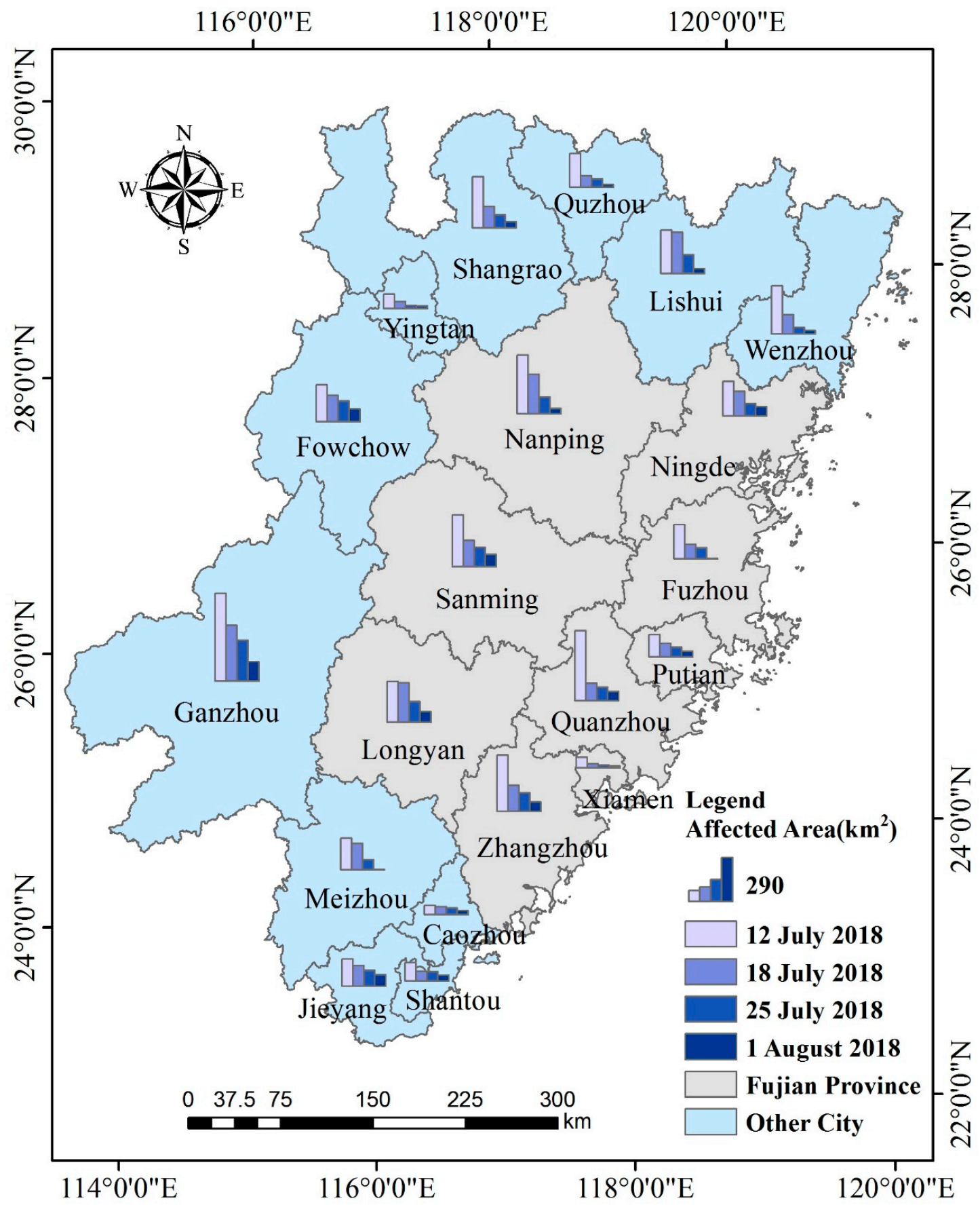

Figure 10. Temporal-spatial changes in affected areas retrieved from PNL images for 20 cities at various times after the typhoon.

\subsubsection{Assessment Based on NTL Image Intensity}

Post-disaster recovery assessments can also be performed by statistically measuring the intensity of the nighttime images of the research area acquired after the disaster. The PNL after the disaster is shown in Figure 11 for 20 prefecture-level cities in the research area. The left ordinate gives the daily PNL after the disaster, and the right ordinate gives the PNL during the first and third weeks after the disaster. The results show that the NTL intensity basically reached a certain level one week after the typhoon disaster. The NTL intensity three weeks after the typhoon disaster is close to that before the 
disaster, indicating that, by the third week after the typhoon disaster, the affected areas of the cities investigated in the research had essentially recovered.

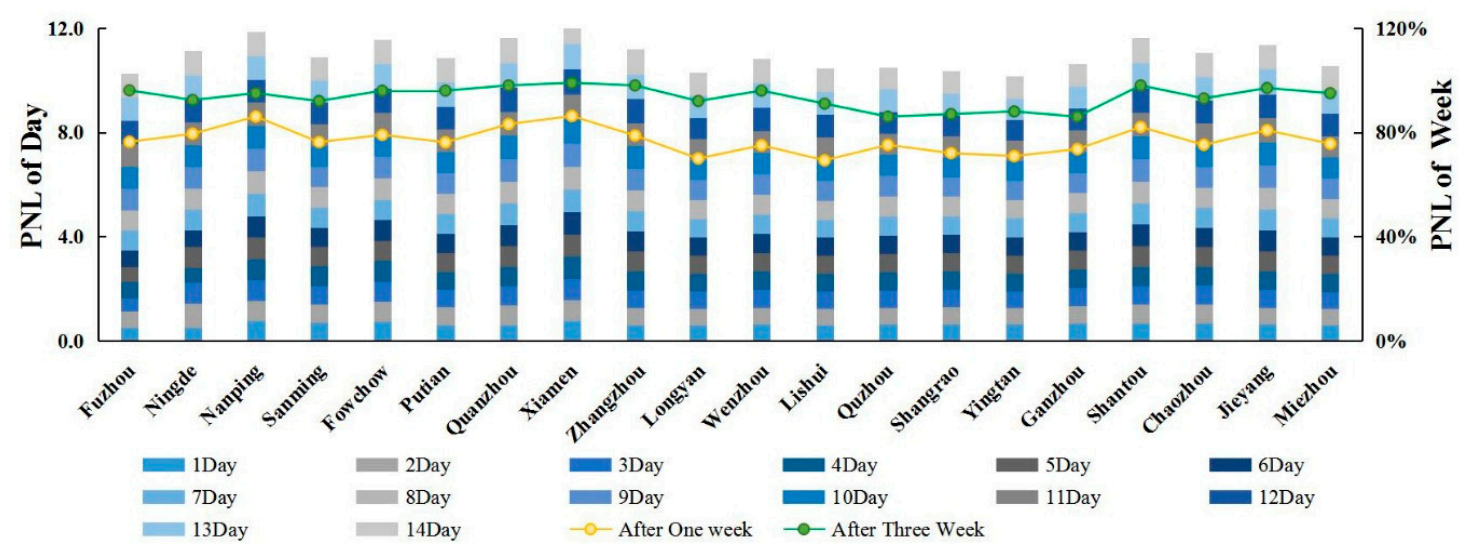

Figure 11. Ratios of post-disaster to pre-disaster nighttime light intensity at different times after the passage of Maria.

\subsubsection{Restoration Status of Representative Cities}

The recovery status of representative cities mainly refers to the temporal-spatial changes in the affected area after the disaster. To more clearly show the temporal-spatial changes, we divide the prefecture-level cities into three types: Those that were strongly affected, normally affected, and slightly affected, and we select, one representative city to show the specific conditions on the first day, the first week, and the third week, respectively, after the disaster and compare the situation with the actual situation of land cover in 2010 (Figure 12a,e,i). From the strongly affected cities, Wenzhou City was selected to statistically display the post-disaster changes. We found that the affected areas were concentrated in the downtown and southern region of Wenzhou city (Figure 12b). The total affected area was $312.75 \mathrm{~km}^{2}$. One week after the disaster, the affected areas were significantly reduced (Figure 12c), and the total affected area was $125.25 \mathrm{~km}^{2}$, indicating a good degree of recovery. Three weeks after the disaster, the NTL in the two seriously affected areas essentially returned to normal (Figure 12d), and the remaining affected area was $62.5 \mathrm{~km}^{2}$, which continued to recover later.

The normally affected cities included Fuzhou city. The affected areas of Fuzhou were mainly concentrated in the urban area of the city (Figure 12f), giving a total affected area of $221.25 \mathrm{~km}^{2}$. One week after the disaster, the affected areas were greatly reduced (Figure 12g), and the affected area was $70.75 \mathrm{~km}^{2}$. Most of the areas had recovered by this time. Three weeks after the disaster, the NTL from the affected areas of Fuzhou city mostly returned to normal (Figure 12h), and the remaining affected area was only $1.5 \mathrm{~km}^{2}$, so the degree of recovery was good.

In those cities that were slightly affected, Yingtan city was used to show the post-disaster situation. Yingtan city was mainly affected in two distinct regions in the middle of the city (Figure 12j), for a total affected area of $93.25 \mathrm{~km}^{2}$. One week after the disaster, the affected area was concentrated in the middle region (Figure 12k), with a total affected area of $34.25 \mathrm{~km}^{2}$. Three weeks after the disaster, the affected area was still concentrated in the middle region (Figure 121), with a total affected area of $17.5 \mathrm{~km}^{2}$. The initially affected areas were restored at this point, with the exception of certain regions. 


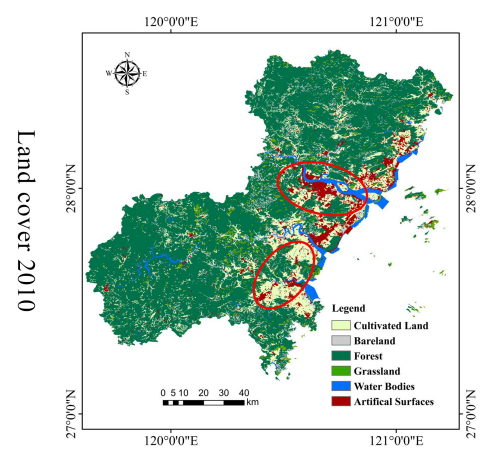

(a)

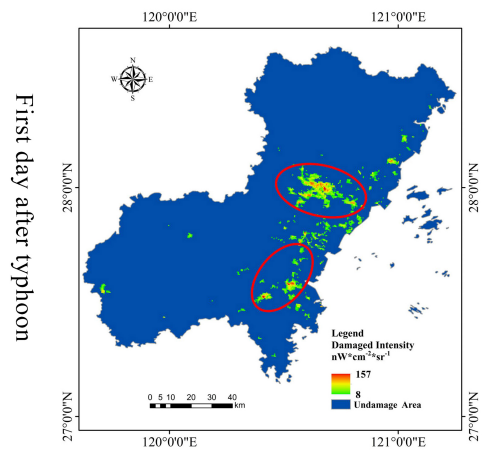

(b)

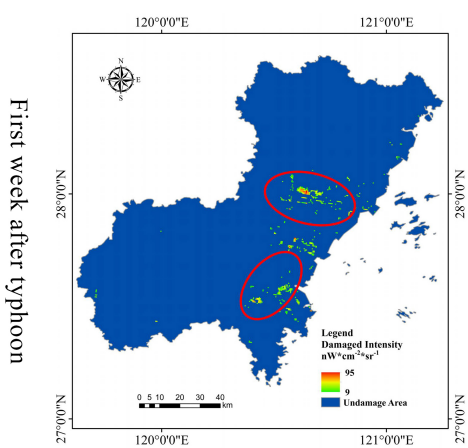

(c)

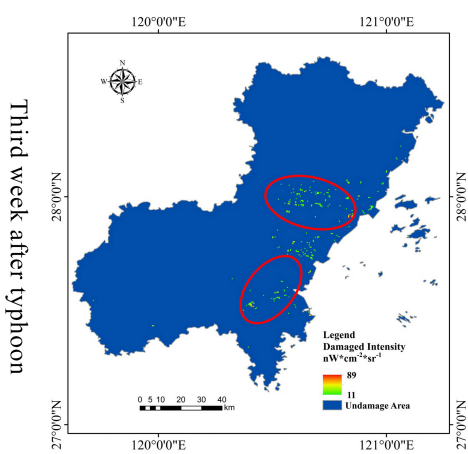

(d)

Wenzhou City

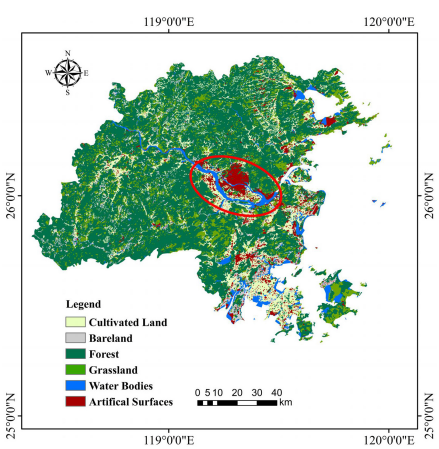

(e)

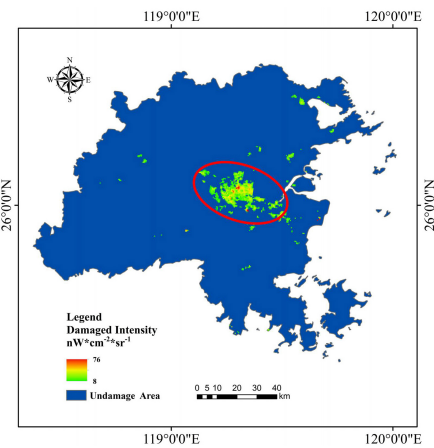

(f)

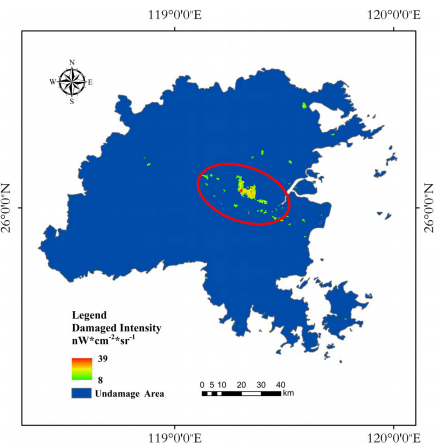

(g)

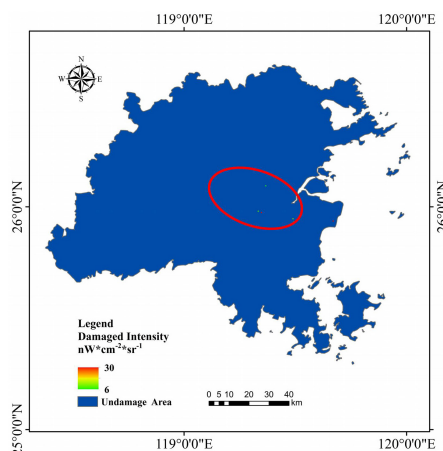

(h)

Fuzhou City

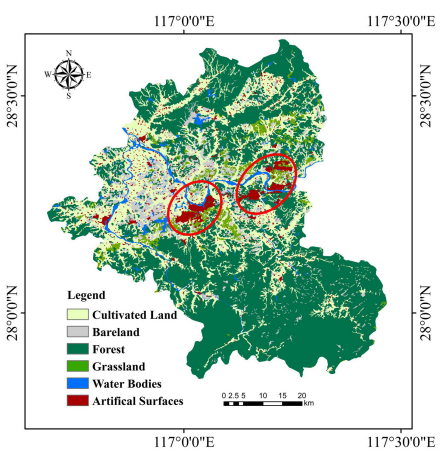

(i)

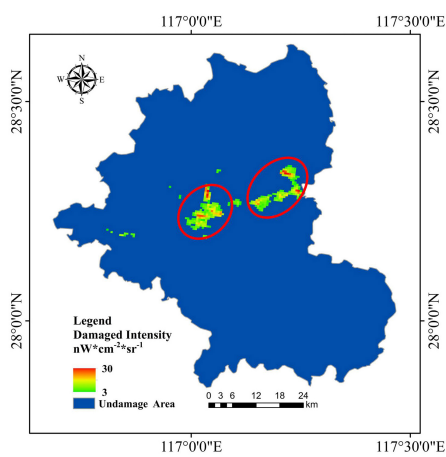

(j)

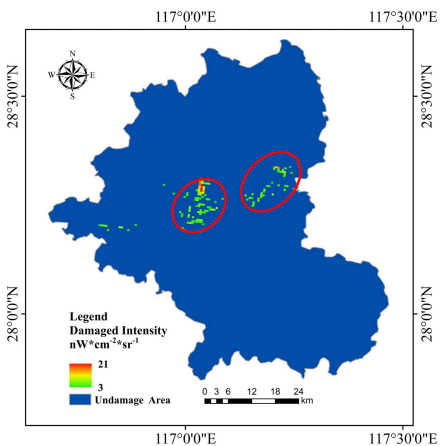

(k)

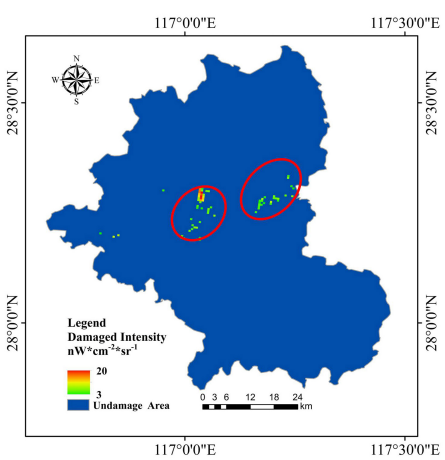

(1)

Yingtan City

Figure 12. Affected status after passage of typhoon Maria for various cities: (a) Land cover 2010 in Wenzhou, the affected status on the first day (b), in the first week (c) and in the third week (d) after the disaster in Wenzhou city, (e) land cover 2010 in Fuhou, the affected status on first day (f), in the first week (g) and in the third week (h) after the disaster in Fuzhou city, (i) land cover 2010 in Yingtan, the affected status on the first day (j), in the first week (k) and in the third week (l) after the disaster in Yingtan city. 
In summary, the urban areas and densely populated areas were most affected by the typhoon, but these areas essentially recovered within three weeks of the disaster. Fuzhou city recovered better after the disaster, but Yingtan city retained some effect from the typhoon, and so its recovery after the disaster was not as smooth. In general, developed cities recovered more rapidly and completely after such disasters, whereas the rate of recovery was slower for less developed cities.

\section{Discussion}

\subsection{Comparison of Different Models}

To model the relationship between NTL data and population and GDP, we constructed a variety of relationship models to connect NTL intensity, NTL area, and weighted NTL index with population and GDP. In each model, the parameters of the model at the prefecture-level and county scales were determined by fitting to different data from the given scale, and the best model for each scale was determined.

For population retrieval, the determinant coefficient of the regression model between NTL density and population density from NPP-VIIRS data was 0.83 , which compares favorably with the results of Sutton et al., who obtained a regression coefficient between NTL data and population density of 0.63 from the DMSP-OLS data [41]. Thus, the model of NTL density and population density based on NPP-VIIRS data proposed herein was more accurate for population retrieval.

For GDP retrieval, this research obtained $R^{2}=0.96$ between the total NTL intensity and the actual GDP at the prefecture-level scale, which is better than the results $\left(R^{2}=0.81\right)$ of Shi et al. [14]. The accuracy of GDP retrieval from NTL data at the county level reached $83.1 \%$. In other work, Li et al. [16] took the relatively simple approach of only considering the relationship between total NTL data and total GDP when constructing their relationship between NTL data and GDP data. The accuracy of retrieval for county-level GDP was only $64.13 \%$. Thus, the accuracy of the GDP retrieved from NTL data in the present study exceeds the previous work [16]. Therefore, for different scales and regions, the method proposed herein provides high-precision retrieval based on various models constructed by fitting different functions. In addition, NTL images contain spatial shape and intensity information, which offer more potential for the retrieval of the disaster intensity.

\subsection{Comparison of Accuracy of Retrieved Characteristics of Natural Disaster}

Liu et al. [72] calculated the distribution of population density from DMSP-OLS data and the actual personal injury statistics within an order-of-magnitude error, which is credible. However, the retrieval error of the earthquake-injured population in Turkey was less than $50 \%$ of the actual survey value, which was due to the serious damage caused by the use of poor construction materials in some cities. Fan et al. [73] used the confusion-matrix method to extract the urban areas affected by the earthquake based on NPP-VIIRS data. The overall accuracy for the two major Chilean earthquakes in 2014 and 2015 were 75\% and 68.7\%, respectively. Previous research [39] estimated an overall accuracy of $75.5 \%$ for the loss caused by the 2015 Gurkha earthquake in Nepal based on the NPP-VIIRS DNB data. The use of NTL data to estimate earthquake damage was not accurate because the light from rescue activities combined with the darkness from power outages introduces serious noise.

The situation is different for typhoon events because the decreased light output in the city after a typhoon is likely to be caused by power outages. Zhao et al. [39] found that the ratio of post-disaster to pre-disaster nighttime light (PNL) was significantly correlated with the power-outage rate $\left(\mathrm{R}^{2}=0.94\right)$. Taking Hudhud as an example, the results show that the predicted blackout rate was basically consistent with the reported blackout rate. Earlier, Cao et al. [37] used DNB data to detect power outages after the Sandy hurricane and found that the percentage of power outages $\left(\operatorname{LO}_{\mathrm{DNB}}=\left(1-\operatorname{Rad}_{\text {post }} / \operatorname{Rad}_{\text {pre }}\right)\right)$ was in good agreement with the reported blackout rate, which further confirmed the correlation between PNL and power-outage rate. In the present research, the retrieved affected areas are mainly affected by power outages. 
This research is based on calculating the affected population. The whole affected population retrieved from the NPP-VIIRS DNB data is $83.2 \%$ of the actual affected population as determined from the previous research [71], which proves the effectiveness of the proposed method. In terms of post-disaster recovery, the research shows that the affected areas in the eastern cities recovered rapidly, which we attribute to the relatively high total GDP of these cities, which increases their disaster resistance. Santiago et al. [74] also concluded that the regions with higher economic development (i.e., stronger disaster resistance) recover faster from natural disasters. Thus, the information retrieved from NTL data is highly accurate and scientific value.

This research shows that the rapid assessment of typhoon disasters based on NPP-VIIRS DNB image data yields excellent results. The accuracy of the affected population obtained from NTL images is as high as $83.2 \%$, which is better than other evaluation methods. This research retrieves the affected area and affected population after a typhoon disaster based on NTL images, which further expands the research into correlations between NTL data and population statistics.

\subsection{Limitations Due to Potential Errors}

This research assesses the affected area and the affected population retrieved from changes in NTL data caused by the typhoon disaster. The results of this evaluation are similar to the actual results. Thus, the method can provide objective data support for timely decisions regarding the management of typhoon disasters. The errors mainly originate from the following sources.

The NPP-VIIRS DNB data are more suitable for areas with relatively high NTL intensity (i.e., urban and developed rural areas). Residential buildings are sparsely distributed in mountainous areas or small villages whose infrastructure and commercial facilities are scattered and underdeveloped, so they emit little light even in normal times, which makes any changes in NTL after a disaster too small for satellites to detect [39], which causes errors in the estimate of affected areas and population. Therefore, the affected areas detected in this research are mainly concentrated in urban areas and a small number of rural areas. On the one hand, this is because the rural population base is small and the affected population is small and, on the other hand, the changes in NTL in mountainous areas and in sparse rural areas are too small to obtain NTL data.

Another limitation of the use of NPP-VIIRS DNB to assess natural disasters is cloud cover. Typhoon disasters are often accompanied by heavy rain and a thick cloud cover, affecting the image quality after such typhoon disasters [39]. In this research, the method of radiation normalization based on the statistics was used to remove the clouds, which improved the result.

In addition, because of the accuracy for ground reference data varies, the true retrieval accuracy may be higher or lower, which depending on the accuracy of the reference data. Thus, the accuracy for ground reference data varies also caused errors. In the future, when more accurate data is acquired in the ground reference data, the assessment results can be further verified.

However, uncertainties remain in the assessment of natural disasters by DNB data. Rescue activities and socioeconomic conditions in different areas also influence the DNB data used for assessing the effects of natural disasters [39]. Water brought by the typhoon can lead to changes in surface reflectance [75]. Furthermore, the DNB data are not suitable for atmospheric correction, especially with regards to the fact that aerosol scatters artificial light, which reduces the detected NTL [76]. In future research, such limitations need to be fully considered by using more effective and comprehensive methods with NTL data.

\section{Conclusions}

The availability of NPP-VIIRS DNB daily data makes it possible to use the NTL data for rapid assessment of typhoon disasters. The results of this research lead to the following conclusions:

(1) Image normalization based on the statistical method reduces the influence of clouds and moonlight and greatly improves the accuracy of change detection due to typhoons. 
(2) Different models can be used to carry out high-precision retrieval at different scales. The accuracy rate of prefecture-level GDP prediction based on different models was higher than at that the county level.

(3) The method we proposed to estimate the affected population is reliable. In addition, the affected population was simultaneously calculated from the affected area. The affected area was thus estimated and extracted with relatively high accuracy.

(4) The developed cities in the eastern part of the research area were more seriously affected than the underdeveloped areas in the western part but recovered faster after the disaster.

This research method has potentials for its applications for rapid and efficient assessment after typhoon disasters in other regions. The information obtained from research results, such as the number of the affected population, the temporal-spatial distribution and degree of the affected region of each city in the study area, which can provide data-based support to enable government policymakers to formulate reasonable decisions for reducing disaster losses and emergency rescue management.

Because of the lack of accurate data on the affected population, the accuracy of the model was determined by using the population and GDP data from the yearbook and the results of news reports. These data have certain limitations, which lead to potential errors in the assessment and predictions. With the emergence of more accurate data, the assessment results can be further improved. In the future, NPP-VIIRS DNB data with a higher resolution will be available and can be applied to other natural disasters. If the influence of cultural factors, such as the differences between urban and rural electricity consumption habits, even national customs, can be fully considered in the different study areas, the models will be more consistent with a real-life situation and allow further verification of the effectiveness of DNB data for assessing typhoon disasters in different areas.

Author Contributions: Y.Z. conceived and performed the research and analyzed the results and wrote the paper; H.W., G.S., L.T., and Y.H. supervised the research and participated in manuscript writing and revision; X.W. and Y.W. participated in data collection and processing. All authors have read and approved this manuscript.

Funding: This research was supported by the National Natural Science Foundation of China (grant no. 41471137 and 41571148), the National Key Research and Development Program of China (grant no. 2016YFC0502902 and 2016YFC0501101), the Strategic Priority Research Program (A) of the Chinese Academy of Sciences (grant no. XDA23030103) and the Open Fund Programs of Big Data Institute of Digital Natural Disaster Monitoring in Fujian (grant no. NDMBD2018004).

Acknowledgments: The authors would like to thank the anonymous reviewers for their constructive comments on an earlier version of this paper.

Conflicts of Interest: The authors declare no conflict of interest.

\section{Appendix A}

Table A1. Regression coefficients between light intensity and population density or GDP in 2016.

\begin{tabular}{|c|c|c|c|c|c|c|c|}
\hline \multicolumn{2}{|c|}{ Region and Fitting Parameters } & \multicolumn{3}{|c|}{$\begin{array}{l}\text { Coefficient between Population } \\
\text { Density with Nighttime Light Density }\end{array}$} & \multicolumn{3}{|c|}{$\begin{array}{l}\text { Coefficient between GDP with } \\
\text { Total Nighttime Light }\end{array}$} \\
\hline Region & fitting function & Slope $C_{1}$ & Constant $\mathrm{C}_{0}$ & $\mathrm{R}^{2}$ & Slope $C_{1}$ & Constant $\mathrm{C}_{0}$ & $\mathrm{R}^{2}$ \\
\hline Entirety & prefecture-level & 65.850 & 188.920 & 0.826 & 0.055 & 104.274 & 0.959 \\
\hline Eastern region & Partition prefecture-level & 59.476 & 349.287 & 0.720 & 0.061 & -413.595 & 0.989 \\
\hline Western region & Partition prefecture-level & 82.829 & 121.317 & 0.141 & 0.044 & 479.658 & 0.577 \\
\hline Entirety & County-level & 112.862 & -145.171 & 0.788 & 0.046 & 53.293 & 0.706 \\
\hline
\end{tabular}


Table A2. Various parameters of sample data based on a statistical radiation normalization method for 20 prefecture-level cities after typhoon Maria.

\begin{tabular}{|c|c|c|c|c|c|c|c|}
\hline \multirow{2}{*}{$\begin{array}{l}\text { Research } \\
\text { Area } \\
\text { Sample }\end{array}$} & \multicolumn{4}{|c|}{$\begin{array}{c}\text { Parameter of Statistical } \\
\text { Radiation Value Normalized }\end{array}$} & \multicolumn{3}{|c|}{$\begin{array}{l}\text { Gaussian Fitting Parameters and } \\
\text { Segmentation Threshold }\end{array}$} \\
\hline & $\begin{array}{c}\text { Mean } \\
\text { Pre-Disaster } \\
\text { Sample }(\mu)\end{array}$ & $\begin{array}{c}\text { Variance } \\
\text { Pre-Disaster } \\
\text { Sample }\left(\sigma^{2}\right)\end{array}$ & $\begin{array}{c}\text { Mean } \\
\text { Post-Disaster } \\
\text { Sample }(\mu)\end{array}$ & $\begin{array}{c}\text { Variance } \\
\text { Post-Disaster } \\
\text { Sample }\left(\sigma^{2}\right)\end{array}$ & $\begin{array}{c}\text { Fitting } \\
\text { Parameters } \\
(\mu)\end{array}$ & $\begin{array}{c}\text { Fitting } \\
\text { Parameters } \\
(\sigma)\end{array}$ & $\begin{array}{l}\text { Segmentation } \\
\text { Threshold }(\tau)\end{array}$ \\
\hline Caozhou & 0.399 & 0.085 & 0.297 & 0.043 & -1.118 & 3.674 & 6.0832 \\
\hline Fowchow & 0.246 & 0.045 & 0.171 & 0.085 & 0.152 & 1.223 & 2.5499 \\
\hline Jieyang & 0.280 & 0.016 & 0.390 & 0.015 & 1.761 & 5.753 & 13.0379 \\
\hline Lishui & 0.217 & 0.047 & 0.212 & 0.088 & 0.308 & 1.839 & 3.9123 \\
\hline Longyan & 0.263 & 0.040 & 0.167 & 0.109 & 0.351 & 1.754 & 5.5442 \\
\hline Meizhou & 1.312 & 0.701 & 0.375 & 0.142 & -1.298 & 4.019 & 6.5796 \\
\hline Nanping & 0.203 & 0.057 & 0.220 & 0.072 & 0.175 & 0.917 & 1.9723 \\
\hline Ningde & 0.323 & 0.071 & 0.554 & 1.274 & 0.441 & 2.509 & 5.3585 \\
\hline Shangrao & 0.226 & 0.039 & 0.181 & 0.103 & 0.219 & 1.039 & 2.2566 \\
\hline Shantou & 0.465 & 0.031 & 0.289 & 0.099 & 6.877 & 10.191 & 26.8508 \\
\hline Wenzhou & 0.407 & 0.100 & 0.278 & 0.068 & 0.338 & 3.579 & 7.3529 \\
\hline Xiamen & 0.811 & 0.258 & 1.179 & 0.102 & 0.929 & 11.160 & 22.8030 \\
\hline Yintang & 0.230 & 0.044 & 0.173 & 0.069 & 0.315 & 1.568 & 3.3886 \\
\hline Zhangzhou & 0.293 & 0.044 & 0.271 & 0.052 & 0.898 & 3.966 & 8.6711 \\
\hline
\end{tabular}

\section{References}

1. Yu, D. Intuitionistic fuzzy theory based typhoon disaster evaluation in Zhejiang Province, China: A comparative perspective. Nat. Hazards 2015, 75, 2559-2576. [CrossRef]

2. Fan, Y.; Wu, W.; Wang, W.; Liu, M.; Wen, Q. Research progress of disaster remote sensing in China. Int. J. Remote Sens. 2016, 20, 1170-1184.

3. Liou, Y.-A.; Liu, J.-C.; Liu, C.P.; Liu, C.-C. Season-Dependent Distributions and Profiles of Seven Super-Typhoons (2014) in the Northwestern Pacific Ocean from Satellite Cloud Images. IEEE Trans. Geosci. Remote Sens. 2018, 56, 2949-2957. [CrossRef]

4. Wang, J.R.; Meneghini, R.; Kumagai, H.; Wilheit, T.T.; Boncyk, W.C.; Racette, P.; Tesmer, J.R.; Maves, B. Airborne active and passive microwave observations of super typhoon Flo. IEEE Trans. Geosci. Remote Sens. 1994, 32, 231-242. [CrossRef]

5. $\quad$ Lee, Y.-S.; Liou, Y.-A.; Liu, J.-C.; Chiang, C.-T.; Yeh, K.-D. Formation of winter supertyphoons Haiyan (2013) and Hagupit (2014) through interactions with cold fronts as observed by multifunctional transport satellite. IEEE Trans. Geosci. Remote Sens. 2017, 55, 3800-3809. [CrossRef]

6. Aubrecht, C.; Fuchs, S.; Neuhold, C. Spatio-temporal aspects and dimensions in integrated disaster risk management. Nat. Hazards 2013, 68, 1205-1216. [CrossRef]

7. Okamura, M.; Bhandary, N.P.; Mori, S.; Marasini, N.; Hazarika, H. Report on a reconnaissance survey of damage in Kathmandu caused by the 2015 Gorkha Nepal earthquake. Soils Found. 2015, 55, 1015-1029. [CrossRef]

8. $\quad$ Li, S.; Sun, D.; Goldberg, M.D.; Sjoberg, B.; Santek, D.; Hoffman, J.P.; DeWeese, M.; Restrepo, P.; Lindsey, S.; Holloway, E. Automatic near real-time flood detection using Suomi-NPP/VIIRS data. Remote Sens. Environ. 2018, 204, 672-689. [CrossRef]

9. Elvidge, C.D.; Baugh, K.E.; Kihn, E.A.; Kroehl, H.W.; Davis, E.R. Mapping city lights with nighttime data from the DMSP Operational Linescan System. Photogramm. Eng. Remote Sens. 1997, 63, 727-734.

10. Miller, S.; Straka, W.; Mills, S.; Elvidge, C.; Lee, T.; Solbrig, J.; Walther, A.; Heidinger, A.; Weiss, S. Illuminating the capabilities of the suomi national polar-orbiting partnership (NPP) visible infrared imaging radiometer suite (VIIRS) day/night band. Remote Sens. 2013, 5, 6717-6766. [CrossRef]

11. Bennett, M.M.; Smith, L.C. Advances in using multitemporal night-time lights satellite imagery to detect, estimate, and monitor socioeconomic dynamics. Remote Sens. Environ. 2017, 192, 176-197. [CrossRef] 
12. Elvidge, C.D.; Cinzano, P.; Pettit, D.; Arvesen, J.; Sutton, P.; Small, C.; Nemani, R.; Longcore, T.; Rich, C.; Safran, J. The Nightsat mission concept. Int. J. Remote Sens. 2007, 28, 2645-2670. [CrossRef]

13. Elvidge, C.D.; Baugh, K.; Zhizhin, M.; Hsu, F.C.; Ghosh, T. VIIRS night-time lights. Int. J. Remote Sens. 2017, 38, 5860-5879. [CrossRef]

14. Shi, K.; Yu, B.; Huang, Y.; Hu, Y.; Yin, B.; Chen, Z.; Chen, L.; Wu, J. Evaluating the ability of NPP-VIIRS nighttime light data to estimate the gross domestic product and the electric power consumption of China at multiple scales: A comparison with DMSP-OLS data. Remote Sens. 2014, 6, 1705-1724. [CrossRef]

15. Zhao, N.; Liu, Y.; Cao, G.; Samson, E.L.; Zhang, J. Forecasting China's GDP at the pixel level using nighttime lights time series and population images. GISci. Remote Sens. 2017, 54, 407-425. [CrossRef]

16. Li, X.; Xu, H.; Chen, X.; Li, C. Potential of NPP-VIIRS nighttime light imagery for modeling the regional economy of China. Remote Sens. 2013, 5, 3057-3081. [CrossRef]

17. Zeng, C.; Zhou, Y.; Wang, S.; Yan, F.; Zhao, Q. Population spatialization in China based on night-time imagery and land use data. Int. J. Remote Sens. 2011, 32, 9599-9620. [CrossRef]

18. Yang, X.; Yue, W.; Gao, D. Spatial improvement of human population distribution based on multi-sensor remote-sensing data: An input for exposure assessment. Int. J. Remote Sens. 2013, 34, 5569-5583. [CrossRef]

19. Min, B.; Gaba, K.M.; Sarr, O.F.; Agalassou, A. Detection of rural electrification in Africa using DMSP-OLS night lights imagery. Int. J. Remote Sens. 2013, 34, 8118-8141. [CrossRef]

20. Shi, K.; Yu, B.; Huang, C.; Wu, J.; Sun, X. Exploring spatiotemporal patterns of electric power consumption in countries along the Belt and Road. Energy 2018, 150, 847-859. [CrossRef]

21. Deng, C.; Lin, W.; Chen, S. Use of smart meter readings and nighttime light images to track pixel-level electricity consumption. Remote Sens. Lett. 2019, 10, 205-213. [CrossRef]

22. Ghosh, T.; Elvidge, C.D.; Sutton, P.C.; Baugh, K.E.; Ziskin, D.; Tuttle, B.T. Creating a global grid of distributed fossil fuel $\mathrm{CO}_{2}$ emissions from nighttime satellite imagery. Energy 2010, 3, 1895-1913. [CrossRef]

23. Shi, K.; Chen, Y.; Li, L.; Huang, C. Spatiotemporal variations of urban $\mathrm{CO}_{2}$ emissions in China: A multiscale perspective. Appl. Energy 2018, 211, 218-229. [CrossRef]

24. Zhao, J.; Ji, G.; Yue, Y.; Lai, Z.; Chen, Y.; Yang, D.; Yang, X.; Wang, Z. Spatio-temporal dynamics of urban residential $\mathrm{CO}_{2}$ emissions and their driving forces in China using the integrated two nighttime light datasets. Appl. Energy 2019, 235, 612-624. [CrossRef]

25. Li, X.; Chen, X.; Zhao, Y.; Xu, J.; Chen, F.; Li, H. Automatic intercalibration of night-time light imagery using robust regression. Remote Sens. Lett. 2013, 4, 45-54. [CrossRef]

26. Zheng, Z.; Chen, Y.; Wu, Z.; Ye, X.; Guo, G.; Qian, Q. The desaturation method of DMSP/OLS nighttime light data based on vector data: Taking the rapidly urbanized China as an example. Int. J. Geogr. Inf. Sci. 2019, 33, 431-453. [CrossRef]

27. Yu, B.; Tang, M.; Wu, Q.; Yang, C.; Deng, S.; Shi, K.; Peng, C.; Wu, J.; Chen, Z. Urban built-up area extraction from log-transformed npp-viirs nighttime light composite data. IEEE Geosci. Remote Sens. Lett. 2018, 15, 1279-1283. [CrossRef]

28. Shi, K.; Huang, C.; Yu, B.; Yin, B.; Huang, Y.; Wu, J. Evaluation of NPP-VIIRS night-time light composite data for extracting built-up urban areas. Remote Sens. Lett. 2014, 5, 358-366. [CrossRef]

29. Wei, Y.; Liu, H.; Song, W.; Yu, B.; Xiu, C. Normalization of time series DMSP-OLS nighttime light images for urban growth analysis with pseudo invariant features. Landsc. Urban Plan. 2014, 128, 1-13. [CrossRef]

30. Zou, Y.; Peng, H.; Liu, G.; Yang, K.; Xie, Y.; Weng, Q. Monitoring urban clusters expansion in the middle reaches of the Yangtze River, China, using time-series nighttime light images. Remote Sens. 2017, 9, 1007. [CrossRef]

31. Gao, B.; Huang, Q.; He, C.; Dou, Y. Similarities and differences of city-size distributions in three main urban agglomerations of China from 1992 to 2015: A comparative study based on nighttime light data. J. Geogr. Sci. 2017, 27, 533-545. [CrossRef]

32. Kohiyama, M.; Hayashi, H.; Maki, N.; Higashida, M.; Kroehl, H.; Elvidge, C.; Hobson, V. Early damaged area estimation system using DMSP-OLS night-time imagery. Int. J. Remote Sens. 2004, 25, 2015-2036. [CrossRef]

33. Cole, T.; Wanik, D.; Molthan, A.; Román, M.; Griffin, R. Synergistic use of nighttime satellite data, electric utility infrastructure, and ambient population to improve power outage detections in urban areas. Remote Sens. 2017, 9, 286. [CrossRef]

34. Huang, Q.; Yang, X.; Gao, B.; Yang, Y.; Zhao, Y. Application of DMSP/OLS nighttime light images: A meta-analysis and a systematic literature review. Remote Sens. 2014, 6, 6844-6866. [CrossRef] 
35. Elvidge, C.; Baugh, K.; Hobson, V.; Kihn, E.; Kroehl, H. Detection of fires and power outages using DMSP-OLS data. In Remote Sensing Change Detection: Environmental Monitoring Methods and Applications; Ross, S., Lunetta, C.D.E., Eds.; Taylor \& Francis: London, UK, 1998; pp. 123-135.

36. Molthan, A.; Jedlovec, G. Satellite observations monitor outages from Superstorm Sandy. Eos Trans. Am. Geophys. Union 2013, 94, 53-54. [CrossRef]

37. Cao, C.; Shao, X.; Uprety, S. Detecting light outages after severe storms using the S-NPP/VIIRS day/night band radiances. IEEE Geosci. Remote Sens. Lett. 2013, 10, 1582-1586. [CrossRef]

38. Wang, Z.; Román, M.; Sun, Q.; Molthan, A.; Schultz, L.; Kalb, V. Monitoring disaster-related power outages using NASA black marble nighttime light product. ISPRS Int. Arch. Photogramm. Remote Sens. Spat. Inf. Sci. 2018, XLII-3, 1853-1856. [CrossRef]

39. Zhao, X.; Yu, B.; Liu, Y.; Yao, S.; Lian, T.; Chen, L.; Yang, C.; Chen, Z.; Wu, J. NPP-VIIRS DNB Daily Data in Natural Disaster Assessment: Evidence from Selected Case Studies. Remote Sens. 2018, 10, 1526. [CrossRef]

40. Briggs, D.J.; Gulliver, J.; Fecht, D.; Vienneau, D.M. Dasymetric modelling of small-area population distribution using land cover and light emissions data. Remote Sens. Environ. 2007, 108, 451-466. [CrossRef]

41. Sutton, P.; Roberts, D.; Elvidge, C.; Meij, H. A comparison of nighttime satellite imagery and population density for the continental United States. Photogramm. Eng. Remote Sens. 1997, 63, 1303-1313.

42. Amaral, S.; Câmara, G.; Monteiro, A.M.V.; Quintanilha, J.A.; Elvidge, C.D. Estimating population and energy consumption in Brazilian Amazonia using DMSP night-time satellite data. Comput. Environ. Urban Syst. 2005, 29, 179-195. [CrossRef]

43. Zhuo, L.; Ichinose, T.; Zheng, J.; Chen, J.; Shi, P.; Li, X. Modelling the population density of China at the pixel level based on DMSP/OLS non-radiance-calibrated night-time light images. Int. J. Remote Sens. 2009, 30, 1003-1018. [CrossRef]

44. Chen, X.; Nordhaus, W. A test of the new VIIRS lights data set: Population and economic output in Africa. Remote Sens. 2015, 7, 4937-4947. [CrossRef]

45. Chou, M.Y.; Lin, C.C.; Yue, J.; Tsai, H.F.; Sun, Y.Y.; Liu, J.Y.; Chen, C.H. Concentric traveling ionosphere disturbances triggered by Super Typhoon Meranti (2016). Geophys. Res. Lett. 2017, 44, 1219-1226. [CrossRef]

46. China Central Meteorological Observatory: Typhoon Network. Available online: http://typhoon.nmc.cn/ web.html (accessed on 1 August 2018).

47. China National Committee for Disaster Reduction. Available online: http://www.jianzai.gov.cn/zxzq/ (accessed on 1 August 2018).

48. NOAA Comprehensive Large Array-Data Stewardship System (CLASS). Available online: https://ngdc.noaa. gov/eog/viirs/download_dbs.html (accessed on 1 August 2018).

49. GLOBELAND30. Available online: http://globallandcover.com/GLC30Download/index.aspx (accessed on 1 August 2018).

50. Chavez, P.S. Image-based atmospheric corrections-revisited and improved. Photogramm. Eng. Remote Sens. 1996, 62, 1025-1035.

51. Eivazi, A.; Kolesnikov, A.; Junttila, V.; Kauranne, T. Variance-preserving mosaicing of multiple satellite images for forest parameter estimation: Radiometric normalization. ISPRS-J. Photogramm. Remote Sens. 2015, 105, 120-127. [CrossRef]

52. Gorroño, J.; Banks, A.C.; Fox, N.P.; Underwood, C. Radiometric inter-sensor cross-calibration uncertainty using a traceable high accuracy reference hyperspectral imager. ISPRS-J. Photogramm. Remote Sens. 2017, 130, 393-417. [CrossRef]

53. Biday, S.G.; Bhosle, U. Radiometric Correction of Multitemporal Satellite Imagery. J. Comput. Sci. 2010, 6, 1027-1036. [CrossRef]

54. Li, W.; Sun, K.; Zhang, H. Algorithm for relative radiometric consistency process of remote sensing images based on object-oriented smoothing and contourlet transforms. J. Appl. Remote Sens. 2014, 8, 083607. [CrossRef]

55. Chen, X.; Vierling, L.; Deering, D. A simple and effective radiometric correction method to improve landscape change detection across sensors and across time. Remote Sens. Environ. 2005, 98, 63-79. [CrossRef]

56. Fan, W.; Sun, S.; Wang, J. Comparison of relative radiometric correction methods for multi-temporal remote sensing imagery. Remote Sens. Inf. 2016, 31, 142-149. (In Chinese)

57. Gadallah, F.; Csillag, F.; Smith, E. Destriping multisensor imagery with moment matching. Int. J. Remote Sens. 2000, 21, 2505-2511. [CrossRef] 
58. Radke, R.J.; Andra, S.; Al-Kofahi, O.; Roysam, B. Image change detection algorithms: A systematic survey. IEEE Trans. Image Process. 2005, 14, 294-307. [CrossRef]

59. Zhang, X.; Zhu, J.; Xu, J. Earthquake disaster information extraction based on night-time lighting images. J. Seismol. Res. 2018, 41, 311-318. (In Chinese)

60. Dai, X.; Khorram, S. The effects of image misregistration on the accuracy of remotely sensed change detection. IEEE Trans. Geosci. Remote Sens. 1998, 36, 1566-1577.

61. Hall, O.; Hay, G.J. A multiscale object-specific approach to digital change detection. Int. J. Appl. Earth Obs. Geoinf. 2003, 4, 311-327. [CrossRef]

62. Deng, S.; Wu, H.; Jiang, T. A study on relative radiometric normalization for remote sensing dynamic monitoring. Remote Sens. Inf. 2008, 4, 71-75. (In Chinese)

63. Desclée, B.; Bogaert, P.; Defourny, P. Forest change detection by statistical object-based method. Remote Sens. Environ. 2006, 102, 1-11. [CrossRef]

64. Zhang, Q.; Seto, K.C. Mapping urbanization dynamics at regional and global scales using multi-temporal DMSP/OLS nighttime light data. Remote Sens. Environ. 2011, 115, 2320-2329. [CrossRef]

65. Chen, J.; Zhuo, L.; Shi, P.; Toshiaki, I. The study on urbanization process in China based on DMSP/OLS data: Development of a light index for urbanization level estimation. Int. J. Remote Sens. 2003, 7, 168-175.

66. Letu, H.; Hara, M.; Yagi, H.; Naoki, K.; Tana, G.; Nishio, F.; Shuhei, O. Estimating energy consumption from night-time DMPS/OLS imagery after correcting for saturation effects. Int. J. Remote Sens. 2010, 31, 4443-4458. [CrossRef]

67. Lo, C. Modeling the population of China using DMSP operational linescan system nighttime data. Photogramm. Eng. Remote Sens. 2001, 67, 1037-1047.

68. Townsend, A.C.; Bruce, D.A. The use of night-time lights satellite imagery as a measure of Australia's regional electricity consumption and population distribution. Int. J. Remote Sens. 2010, 31, 4459-4480. [CrossRef]

69. "Maria" Has Affected Nearly 250,000 People and Caused Direct Economic Losses of 1.57 Billion Yuan in Ningde. Available online: http://www.ndwww.cn/xw/ndxw/2018/0713/90568.shtml (accessed on 13 July 2018).

70. Typhoon "Maria” Strikes, Catastrophe Insurance Becomes More Important. Available online: https: //baijiahao.baidu.com/s?id=1607379570974150028\&wfr=spider\&for=pc (accessed on 30 July 2018).

71. Lv, J. Flood situation and disaster in China during July 2018. China Flood Drought Manag. 2018, $28,74$. (In Chinese)

72. Liu, S. A try to import a new basic data for fast evaluation of earthquake hazards: Utilizing the DMSP/OLS satellite nighttime light data. J. Inst. Disaster Prev. 2012, 14, 70-75. (In Chinese)

73. Fan, X.; Nie, G.; Deng, Y.; An, J.; Zhou, J.; Li, H. Rapid detection of earthquake damage areas using VIIRS nearly constant contrast night-time light data. Int. J. Remote Sens. 2019, 40, 2386-2409. [CrossRef]

74. Santiago, J.S.S.; Manuela, W.S., Jr.; Tan, M.L.L.; Saňez, S.K.B.; Tong, A.Z.U. Agency-driven post-disaster recovery: A comparative study of three Typhoon Washi resettlement communities in the Philippines. Int. J. Disaster Risk Reduct. 2018, 27, 480-489. [CrossRef]

75. Kerekes, J.P.; Strackerjan, K.; Salvaggio, C. Spectral reflectance and emissivity of man-made surfaces contaminated with environmental effects. Opt. Eng. 2008, 47, 106201.

76. Johnson, R.S.; Zhang, J.; Hyer, E.J.; Miller, S.D.; Reid, J.S. Preliminary investigations toward nighttime aerosol optical depth retrievals from the VIIRS Day/Night Band. Atmos. Meas. Tech. 2013, 6, 1245-1255. [CrossRef]

(C) 2019 by the authors. Licensee MDPI, Basel, Switzerland. This article is an open access article distributed under the terms and conditions of the Creative Commons Attribution (CC BY) license (http://creativecommons.org/licenses/by/4.0/). 